\title{
Phosphorylation-Dependent Low-Frequency Depression at Phasic Synapses of a Crayfish Motoneuron
}

\author{
Lorelei B. Silverman-Gavrila, Peter M. R. Orth, and Milton P. Charlton \\ Department of Physiology, University of Toronto, Toronto, Ontario, Canada M5S 1A8
}

Extremes in presynaptic differentiation can be studied at the crayfish leg extensor muscle where, on the same muscle fiber, one motoneuron makes "phasic" depressing synapses that have a high probability of neurotransmitter release and another motoneuron makes "tonic," low-probability, facilitating synapses. The large motor axons permit intracellular access to presynaptic sites. We examined the role of phosphorylation during low-frequency depression (LFD) in the relatively little studied phasic synapses.

LFD occurs with stimulation at $0.2 \mathrm{~Hz}$ and develops with time constants of 4 and 105 min to reach $>50 \%$ depression of transmitter release in $60 \mathrm{~min}$ similar to long-term depression in mammals. LFD is not associated with changes in postsynaptic sensitivity to transmitter and thus is a presynaptic event, although it is not accompanied by changes in the presynaptic action potential. Blockade of protein kinases accelerated the slow phase of LFD, but stimulation of kinases reduced depression. Blockade of protein phosphatases 1A/2A reversed the slow phase. When calcineurin was inhibited, both phases of LFD were abolished, and facilitation occurred instead. Immunostaining showed calcineurin-like immunoreactivity in synaptic terminals. Recovery from LFD occurred in $\sim 1 \mathrm{~h}$ if stimulation frequency was reduced to $0.0016 \mathrm{~Hz}$. Recovery was blocked by kinase inhibition.

This study shows that phosphorylation-dependent mechanisms are involved in LFD and suggests that exocytosis is controlled by conditions that shift the balance between phosphorylated and unphosphorylated substrates. The shift can occur by alteration in the relative activities of protein kinases and phosphatases.

Key words: synaptic plasticity; low-frequency depression; protein kinase A; protein kinase C; calcineurin; presynaptic differentiation

\section{Introduction}

There is a great diversity in performance of presynaptic terminals attained through development or by learning and memory mechanisms. The synapses of Crustacean neuromuscular junctions provide an extraordinary opportunity to study presynaptic differentiation. For instance, at individual fibers of the crayfish leg extensor muscle, one motor neuron makes synapses that have a high probability of transmitter release and depress easily with low-frequency stimulation. On the same muscle fiber, another motoneuron makes tonic synapses that have a probability of transmitter release hundreds of times lower than that of the phasic synapses, but the probability increases dramatically with repetitive stimulation (Bradacs et al., 1997; Atwood and Karunanithi, 2002).

These synapses are particularly suited for the study of presynaptic differentiation, because their large axons allow recording of action potentials (APs) and injection of substances to modify

Received June 30, 2004; revised Feb. 11, 2005; accepted Feb. 15, 2005.

This work was supported by a Canadian Institutes of Health Research grant to M.P.C. and a Natural Sciences and Engineering Research Council of Canada Postdoctoral Fellowship to L.B.S.-G. We thank Dr. J. MacDonald for criticism of this revised manuscript.

Correspondence should be addressed to Milton P. Charlton, Department of Physiology, University of Toronto Medical Sciences Building, Room 3308, 1 King's College Circle, Toronto, Ontario, Canada M5S 1A8. E-mail: milton@spine.med.utoronto.ca.

Peter M. R. Orth's present address: Cardiome Pharma Corporation, 6190 Agronomy Road, Sixth Floor, Vancouver, British Columbia, Canada V6T 1 Z3.

DOI:10.1523/JNEUROSCI.4908-04.2005

Copyright $\odot 2005$ Society for Neuroscience $\quad$ 0270-6474/05/253168-13\$15.00/0 transmitter release (Hua et al., 1998; Hua and Charlton, 1999). Furthermore, the development of diverse presynaptic types on the same postsynaptic cell makes it unlikely that the presynaptic diversity is attributable to postsynaptic influences. Thus, the factors that cause presynaptic diversity can be sought in the presynaptic cells alone.

Crayfish neuromuscular synapses undergo two forms of longterm plasticity, long-term facilitation (LTF) (Wojtowicz and Atwood, 1986; Beaumont et al., 2001) and low- frequency depression (LFD) (Kennedy and Takeda, 1965), in addition to posttetanic potentiation (Delaney et al., 1989). LFD is a longlasting depression in the amplitude of EPSPs that occurs during very low-frequency stimulation of some Crustacean phasic-type motoneurons (Kennedy and Takeda, 1965; Bryan and Atwood, 1981) as well as mammalian spinal $I_{\mathrm{a}}$ afferents (Kudo and Yamada, 1985). In the hippocampus, the balance of protein kinase and phosphatase activity determines the expression of specific forms of synaptic plasticity: long-term depression (LTD) or long-term potentiation (Coussens and Teyler, 1996). A decline in the quantity of phosphorylated substrate mediates mammalian LTD (Hansel and Linden, 2000; Ramakers et al., 2000). LTD of synaptic transmission induced by low-frequency stimulation of afferents in rat hippocampus involves calcineurin (Yasuda et al., 2003) protein phosphatase 1 (PP1) and protein phosphatase $2 \mathrm{~A}$ (Mulkey et al., 1993). Little is known about the mechanism of LFD in invertebrate synapses.

Because phosphorylation of synaptic substrates plays a key 
role in regulating the strength of synaptic transmission in both Crustacean (Dixon and Atwood, 1989a; Swain et al., 1991; Beaumont et al., 2001) and mammalian nervous systems (Tokuda and Hatase, 1998), we tested the hypothesis that LFD at phasic synapses at crayfish leg extensor muscles involves changes in phosphorylation. We found that LFD does not involve reduction in quantal amplitude or presynaptic action potentials. LFD is a presynaptic phenomenon that involves the activity of multiple phosphatases; kinase activity is required for recovery.

\section{Materials and Methods}

Animals and preparations. Crayfish (Procambarus clarkia; $\sim 6 \mathrm{~cm}$ long; Atchafalaya Biological Supply, Aceland, LA; Niles Biological, Sacramento, CA) were maintained at $12-18^{\circ} \mathrm{C}$ in an aquarium with circulating water and were fed lentils. Animals were used within $20 \mathrm{~d}$ of delivery, because those that were held longer gave inconsistent rates of LFD. The first or second walking leg was removed and pinned down to Sylgard (Dow Corning, Midland, MI) in a Petri dish. The proximal end of the leg was inserted into a "cuff" electrode consisting of a SILASTIC tube containing a platinum wire, and the entire leg was covered with a physiological saline solution (in mM: $205 \mathrm{NaCl}, 5.4 \mathrm{KCl}, 13.5 \mathrm{CaCl}_{2}, 2.7 \mathrm{MgCl}_{2}$, and 10 HEPES, pH 7.4) (Van Harreveld, 1936). To expose the extensor muscle, the cuticle of the lateral aspect of the carpopodite was cut out along with the underlying flexor muscle using a scalpel. The main leg nerve and tendons lying medial to the extensor muscle were carefully cut out and removed, leaving the exposed medial surface of the extensor muscle as well as the phasic and tonic axons. To minimize the contraction during stimulation, the extensor muscle was slowly stretched until axonal stimulation resulted in little or no movement.

Intracellular recordings. To assess neurotransmitter release, we stimulated the phasic axon and measured EPSPs in the extensor muscle. The axon was electrically stimulated either by the cuff electrode or by an intracellular microelectrode. To stimulate with the intracellular microelectrode (10-20 M $\Omega ; 3 \mathrm{M} \mathrm{KCl})$, current pulses were applied through the intra-axonal microelectrode using a stimulator coupled to the breakaway circuit of the preamplifier (model IE-201; Warner Instruments, Hamden, CT). When the phasic axon was stimulated via the cuff electrode, we considered that recordings originate from the phasic stimulation if changes in stimulus current caused a simultaneous disappearance and reappearance of both the action potential recorded from the phasic axon and EPSP from the muscle. EPSPs were recorded by a second microelectrode (3-15 $\mathrm{M} \Omega ; 3 \mathrm{M} \mathrm{KCl})$ inserted into a muscle fiber midway along the length of the muscle (Bradacs et al., 1997). The tonic synapses rarely release any quanta after a single stimulus and thus do not contribute significantly to the measurements presented here. Microelectrodes (Sutter Instruments, Novato, CA) were pulled on a Brown-Flaming micropipette puller (model P-80/PC or P-87; Sutter Instruments).

Data collection and analysis. Preamplifier signals $(10 \times$ gain $)$ were lowpass filtered (four-pole Bessel) at $2 \mathrm{kHz}$ and further amplified $(10-100 \times)$ by a second amplifier (model LPF202; Warner Instruments). A Digidata 1200 interface board (Axon Instruments, Foster City, CA) controlled by a personal computer-based data acquisition program Tomahacq (T. A. Goldthorpe, University Health Network, Toronto, Ontario, Canada) converted analog signals to digital signals at $10 \mathrm{kHz}$.

We measured the peak amplitude or the maximum rate of rise of EPSPs. When the first several EPSPs produced by the phasic axon were so large that they evoked muscle action potentials, we measured the maximum slope of the EPSP rising phase between time points that excluded the action potential. There was an excellent correlation between measurements of EPSP slope and EPSP amplitude.

In some experiments, signals were low-pass filtered at $5 \mathrm{kHz}$ and further amplified $10 \times$ (model LPF202; Warner Instruments) and digitized by a PowerLab/4sp data acquisition system (AD Instruments, Round Rock, TX) using Scope for Windows v.3.6 program (AD Instruments).

Data are presented as the mean and SE. Curve fitting to the time course of LFD was done by SigmaPlot (Systat Software, Richmond, CA) using nonlinear regression.

In some experiments, we made intracellular recordings from presyn- aptic sites. The small size of presynaptic boutons and their complicated geometry (Bradacs et al., 1997) preclude accurate determination of their membrane potentials. Instead, we analyzed resting potential, maximum amplitude of AP, afterdepolarization at $2 \mathrm{~ms}$ after AP peak, and duration of AP at half-maximal peak voltage from presynaptic axons recorded close to transmitter release sites. These parameters were obtained for the first AP recorded and after 30 and $60 \mathrm{~min}$ of LFD at $0.2 \mathrm{~Hz}$ or $10 \mathrm{~min}$ after drug treatments when effects were maximal. Differences between measurements were tested for statistical significance using paired two-tailed $t$ tests where $p>0.05$ indicates no significant difference.

Miniature EPSPs. To enhance spontaneous quantal release at phasic synapses relative to the tonic synapses, a narrow secondary branch of the phasic axon was gradually and continuously depolarized by positive current injected through a high-resistance $(30-120 \mathrm{M} \Omega ; 3 \mathrm{M} \mathrm{KCl})$ intracellular microelectrode (Atwood et al., 1987). This steady depolarization resulted in a marked increase in the frequency of phasic synapse miniature EPSPs (mEPSPs) that could be detected by a low-resistance $(2-7$ $\mathrm{M} \Omega ; 3 \mathrm{M} \mathrm{KCl})$ microelectrode in the muscle fiber near $(100-200 \mu \mathrm{m})$ the site of presynaptic depolarization. Smaller-diameter muscle fibers were preferred in these experiments, because mEPSPs recorded on these fibers were larger because of the relatively greater input resistance. mEPSPs were detected and amplitudes analyzed manually using Whole Cell Analysis Program V3.2.1 (John Dempster, University of Strathclyde, Glasgow, UK). mEPSP amplitudes were plotted, and differences in amplitude distribution were tested for statistical significance using the nonparametric Kolgomorov-Smirnov test $(p<0.05)$.

Drug application. We assessed the effects on neurotransmission of the following cell-permeant modulators of kinases and phosphatases: okadaic acid K-salt (OA), bisindolylmaleimide I (GF), tacrolimus (FK-506), rapamycin, cAMPS-Rp-isomer tetraethylammonium (TEA)-salt, adenosine $3^{\prime}, 5^{\prime}$-cyclic monophosphorothioate Rp-isomer, triethylammonium salt (Rp-cAMP), cAMPS-Sp-isomer TEA-salt adenosine $3^{\prime}, 5^{\prime}$ cyclic monophosphorothioate Sp-isomer (Sp-cAMP) (Calbiochem, La Jolla, CA), phorbol 12-myristate13-acetate (PMA), 4- $\alpha$-PMA-(4- $\alpha$ phorbol 12-myristate 13-acetate), staurosporine (Sigma-Aldrich, Oakville, ON), and permeant calcineurin autoinhibitory peptide (Calbiochem). Drugs were dissolved in DMSO or $\mathrm{H}_{2} \mathrm{O}$ as stock solution (1-10 mM) and were applied to the $2 \mathrm{ml}$ static bath and mixed thoroughly. Final DMSO concentrations during experiments never exceeded $0.2 \%(\mathrm{v} / \mathrm{v})$. Control recordings indicate that this concentration of DMSO does not alter LFD (data not shown). Drug concentration was chosen empirically based on dose-effect trials and on previous published concentrations used in crayfish [Rp-cAMPS, rapamycin (Beaumont et al., 2001), staurosporine, GF, PMA (Friedrich et al., 1998), OA (Swain et al., 1991; Lin and Fu, 2005), Sp-cAMPS, FK-506 (J. E. Swain and M. P. Charlton, unpublished observation)] or in other invertebrates such as Aplysia (FK-506) (Sharma et al., 2003), Mytilus (calcineurin autoinhibitory peptide) (Yamada et al., 2004), and Drosophila (FK-506) (Kuromi et al., 1997).

Immunocytochemistry: double immunolabeling with anti-calcineurin $B$ and anti-syntaxin $1 a-1 b$ antibodies. To obtain evidence for the presence of calcineurin in presynaptic crayfish axon terminals, we double stained for calcineurin B and syntaxin (a presynaptic protein anchored to the cytoplasmic surface of terminal membranes) as a synaptic compartment marker. Dissected preparations of crayfish leg extensor muscles and abdominal nerve cord and Drosophila Canton S (CS) third-instar larvae were fixed for $1 \mathrm{~h}$ at room temperature in 3\% paraformaldehyde and $4 \%$ sucrose in crayfish saline or HL3 Drosophila saline (in mM: $70 \mathrm{NaCl}, 5$ $\mathrm{KCl}, 20 \mathrm{MgCl}_{2} \cdot 6 \mathrm{H}_{2} \mathrm{O}, 1.5 \mathrm{CaCl}_{2} \cdot \mathrm{H}_{2} \mathrm{O}, 10 \mathrm{NaHCO}_{3}, 5$ trehalose, 115 sucrose, and $5 \mathrm{~N}, \mathrm{~N}$-Bis(2-hydroxyethyl)-2-aminoethanesulfonic acid, $\mathrm{pH}$ 7.2) (Stewart et al., 1994). The fixed specimens were placed in individual wells of a multiwell plate (Dow Corning) and washed for 15 min with three changes of saline. Nonspecific antibody binding was blocked by incubation for $1 \mathrm{~h}$ at $4^{\circ} \mathrm{C}$ in $1 \%$ bovine serum albumin, $1 \%$ skim milk powder, and $0.1 \%$ Triton X-100 for permeabilization in saline. Next, specimens were incubated overnight at $4^{\circ} \mathrm{C}$ with the following primary antibodies: rabbit polyclonal against calcineurin $\mathrm{B} \alpha$ (AB1699; Chemicon, Temecula, CA) diluted 1:100 and monoclonal antisyntaxin $1 \mathrm{a}-1 \mathrm{~b}$ mouse IgG 602 antibody (generous gift from Dr. M. Takahashi, Kitasato 
University School of Medicine, Sagamihara-shi, Japan) diluted 1:1000 in saline containing $0.1 \%$ Triton $\mathrm{X}-100$. After this incubation, tissues were washed five times for $5 \mathrm{~min}$ each and primary antibodies were detected with secondary antibodies Alexa Fluor 568 goat anti-rabbit $\operatorname{IgG}(\mathrm{H}+\mathrm{L})$ and Alexa Fluor 488 goat anti-mouse IgG $(\mathrm{H}+\mathrm{L})$ highly cross-adsorbed (Molecular Probes, Eugene, OR) diluted 1:1000 in saline plus 0.1\% Triton $\mathrm{X}-100$ for $1 \mathrm{~h}$ at $4^{\circ} \mathrm{C}$ followed by five washes at $5 \mathrm{~min}$ interval in saline plus $0.1 \%$ Triton X-100 to remove the secondary antibodies. Control preparations without the primary antibodies showed no staining with secondary antibodies (data not shown). Thin slices of the muscle surface made with a razor-blade scalpel were mounted on slides in slow-fade Antifade kit (Molecular Probes) and imaged with a Leica (Heidelberg, Germany) TCS LS confocal laser-scanning microscope and using 488 and $568 \mathrm{~nm}$ excitation lines and either a $63 \times$ numerical aperture (NA), $1.32-0.6$ oil CS, working distance $\alpha 0.17 / \mathrm{D}$ objective lens or $40 \times \mathrm{NA}$, $1.25-0.75$ oil, $\alpha 0.17 /$ E. Images from different focal planes were stacked as layers and combined in projected images. We examined 12 crayfish extensor muscles, four crayfish nerve cords, and four Drosophila larval CNS preparations.

Western blotting. Antibodies were tested for specificity by using Western blot analysis of proteins extracted from crayfish nerve cords and whole Drosophila larvae. Protein extracts from crayfish ventral nerve cord and Drosophila CS third-instar larvae were obtained by freezing in liquid nitrogen and homogenization in a protein lysis buffer containing $50 \mathrm{~mm}$ Tris- $\mathrm{HCl}, \mathrm{pH} 6.8,100 \mathrm{~mm}$ dithiotreitol, $2 \%$ SDS and $10 \%$ glycerol, followed by boiling for $10 \mathrm{~min}$, centrifugation at $12,000-18,000 \times g$ for $10 \mathrm{~min}$, and collection of the supernatant. Protein extracts were analyzed by SDS-PAGE on a ready-made $10 \%$ gel (Bio-Rad, Hercules, CA) and transferred to nitrocellulose membrane using a Mini-Protean III electrophoresis unit and Mini-Trans-Blot system (Bio-Rad). Blots were then probed with anti-calcineurin $\mathrm{B} \alpha$ (Chemicon) or $\mathrm{A} \alpha$ (07-067; Upstate Biotechnology, Chicago, IL) rabbit polyclonal IgG antibody (1:500) and then with goat anti-rabbit IgG secondary antibody conjugated to horseradish peroxidase (1:5000; Upstate Biotechnology). The immunodecorated protein signals were detected by enhanced chemiluminescence (ECL) using an ECL reagent kit (Amersham Biosciences, Baie d'Urfe, Canada), light-sensitive imaging film (Clonex, Markham, Ontario, Canada), and Konica film processor SRX-101A (Konica, Tokyo, Japan).

\section{Results \\ LFD is a frequency-dependent process and occurs in two phases}

We first examined the stability of phasic extensor synapses to determine whether they could be used in experiments on the mechanism of depression. When stimulated at $0.0016 \mathrm{~Hz}$, transmitter release, measured as EPSP amplitude, remained stable for $2 \mathrm{~h}(n=9)$ to $3 \mathrm{~h}(n=3)$. When the stimulation frequency was subsequently increased to $0.2 \mathrm{~Hz}$, LFD occurred (Fig. $1 A$ ). This showed that the depression of neurotransmitter release was not attributable to deterioration of the preparations during the recording period, which was usually shorter in the other experiments reported here.

We then characterized the frequency dependence and kinetics of synaptic depression. Some Crustacean phasic synapses stimulated at low rates show depression of synaptic responses (Bruner and Kennedy, 1970; Zucker and Bruner, 1977; Lnenicka, 1991; Bradacs et al., 1997), but the time course of depression has not been investigated at the phasic synapses of leg extensor muscles. LFD was elicited by stimulating the phasic axon at $0.2 \mathrm{~Hz}$ for 90 min (Fig. $1 B$ ), and transmitter release was measured as the maximum slope of the rising phase of the EPSP. Measurements were normalized to the first EPSP. The time course of transmitter release decay was fitted to a biexponential curve (Fig. $1 B$ ) with time constants $\tau_{\mathrm{I}}=4 \mathrm{~min}$ and $\tau_{\mathrm{II}}=105 \mathrm{~min}$. Previous reports on LFD at crayfish motor giant axon also found an initial fast phase followed by a longer-lasting slow phase (Bruner and Kennedy,
1970). The biexponential decay may indicate that two distinct mechanisms contribute to LFD.

The rate of LFD depended on the stimulation frequency (Fig. 1C). Stimulation at $0.003 \mathrm{~Hz}$ caused significantly less depression after $60 \mathrm{~min}$ than at $0.2 \mathrm{~Hz}$. $\tau_{\mathrm{II}}$ was more affected than $\tau_{\mathrm{I}}$ by reducing the frequency of stimulation $\left(\tau_{\mathrm{I}(0.2 \mathrm{~Hz})}=4 \mathrm{~min} ; \tau_{\mathrm{I}(0.003 \mathrm{~Hz})}=6 \mathrm{~min}\right.$; $\left.\tau_{\mathrm{II}(0.2 \mathrm{~Hz})}=105 \mathrm{~min} ; \tau_{\mathrm{II}(0.003 \mathrm{~Hz})}=455 \mathrm{~min}\right)$, suggesting that the two putative mechanisms that regulate LFD are differentially affected by stimulation frequency. Almost no depression could be obtained with $0.0016 \mathrm{~Hz}$ stimulation (Figs. $1 A, C, 9 A)$. In comparison, Zucker and Bruner (1977) found biphasic and frequency-dependent depression $(0.02$ and $0.005 \mathrm{~Hz}$ ) at phasic synapses on abdominal extensor muscles of crayfish. Bradacs et al. (1997) found that depression at leg extensor phasic synapses could be almost total when stimulated at 5 $\mathrm{Hz}$, although the time course varied between 5 and $50 \mathrm{~min}$ in four preparations.

\section{LFD is attributable to a decline in transmitter release}

To determine whether LFD is caused by a reduction in the sensitivity of postsynaptic muscle cells to the transmitter, we analyzed mEPSPs resulting from the asynchronous release of individual quanta before and after LFD. Usually, changes in amplitude of mEPSPs are caused by postsynaptic factors, whereas changes in frequency of mEPSPs are attributable to presynaptic factors. Examples of mEPSP recordings before $(a)$ and after $(b) 60$ min of 0.2 $\mathrm{Hz}$ stimulation that resulted in $>50 \%$ reduction in evoked transmitter release are shown in Figure $2 A$. An example experiment is shown in Figure $2 B$, in which 96 mEPSPs were analyzed both before and after LFD. The mean mEPSP amplitude before LFD was not significantly different from the mean occurring after LFD (138 $\mu \mathrm{V}$ before depression; $143 \mu \mathrm{V}$ after depression; paired $t$ test; $p>0.05)$. Because the amplitudes of quantal events are not necessarily distributed normally (Bittner and Harrison, 1970), the nonparametric Kolgomorov-Smirnov (KS) test was also used. Figure $2 C$ is a cumulative fraction plot of the same data as in Figure $2 B$. This plot was used to test statistically for differences between the two amplitude distributions with the KS test. No significant difference was found $(p>0.1)$ between the distribution of mEPSP amplitudes before and after LFD $(n=3)$. Because we found no evidence that LFD results from postsynaptic receptor desensitization or a decline in the amount of neurotransmitter comprising a quantum, we conclude that LFD is the result of a decline in the number of quanta released per stimulus.

\section{Presynaptic action potential failure does not cause depression} The peak voltage of the presynaptic AP has a major effect on the amount of transmitter released (Katz and Miledi, 1967). To examine the possibility that changes in the presynaptic AP cause LFD, we simultaneously recorded presynaptic and postsynaptic potentials during LFD. The presynaptic AP changed very little during LFD (Fig. $2 \mathrm{Da}, \mathrm{Db}$ ). We analyzed (five experiments) average axon resting potential, maximum amplitude of AP, afterdepolarization at $2 \mathrm{~ms}$ after AP peak, and duration of AP at halfmaximal peak voltage for the first AP after 30 and 60 min of LFD at $0.2 \mathrm{~Hz}$. Paired two-tail $t$ tests showed no significant differences in these parameters, except for the afterdepolarization, which increased from $5.4 \mathrm{mV}$ in the first $\mathrm{AP}$ to $7.5 \mathrm{mV}$ in an $\mathrm{AP}$ at 60 min. Because Wojtowicz and Atwood (1984) showed that a reduction of $>20 \mathrm{mV}$ in peak voltage of the presynaptic AP was necessary to reduce transmitter release by $50 \%$ (crayfish opener synapses), we conclude that changes in APs do not cause LFD, although we cannot be certain that changes in AP that we re- 

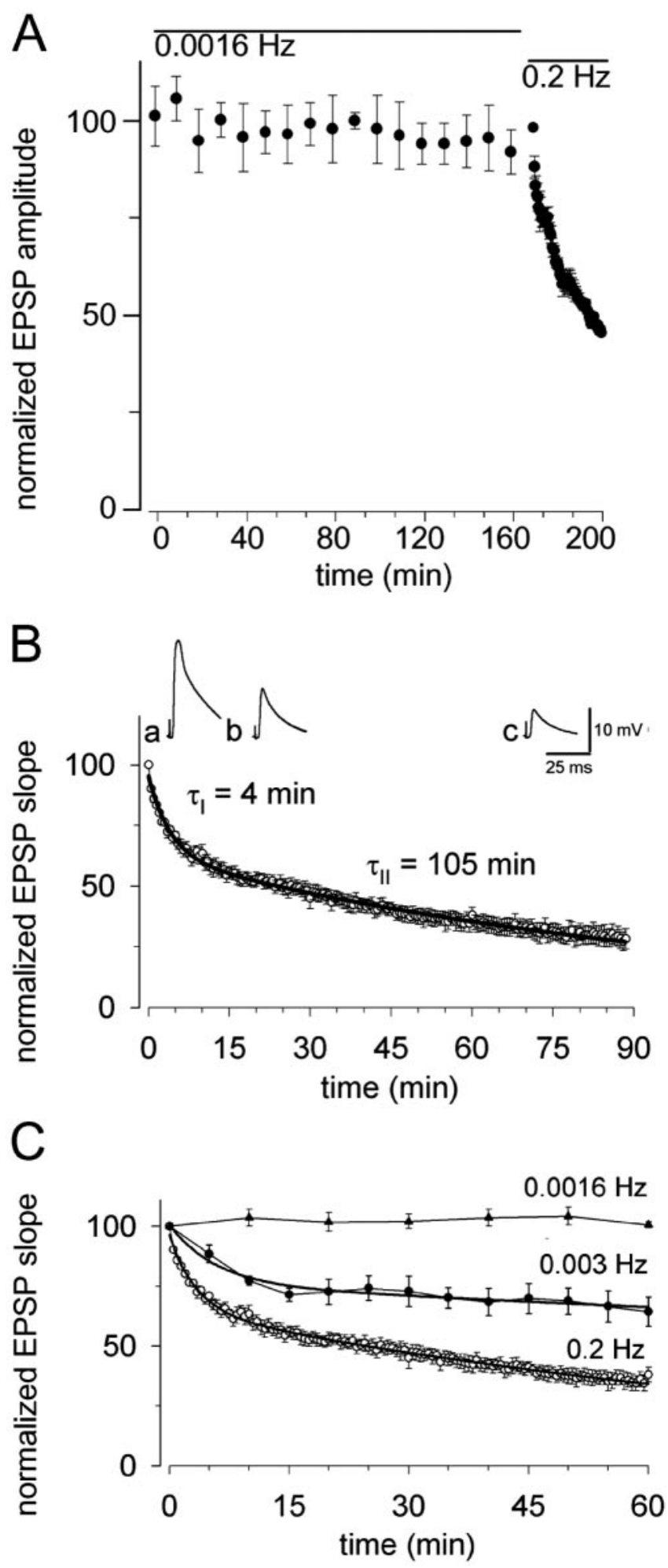

Figure 1. LFD is a stimulation frequency-dependent biexponential decline in transmitter release. $\boldsymbol{A}$, Neurotransmitter release remained stable for 170 min when stimulated at $0.0016 \mathrm{~Hz}$, but LFD occurred when the frequency was increased to $0.2 \mathrm{~Hz}$. At $0.2 \mathrm{~Hz}$, each point is the average of six consecutive stimuli in three experiments \pm SE. $\boldsymbol{B}$, Low-frequency stimulation at $0.2 \mathrm{~Hz}$ elicited a biphasic dedine in transmitter release with time constants $\tau_{1}=4 \mathrm{~min}$ and $\tau_{\|}=105 \mathrm{~min}$ (average data from 4 experiments $\pm \mathrm{SE}$ ). $\boldsymbol{a}$ - $\boldsymbol{c}$, Representative EPSPs at 0, 15, and 90 min, respectively. The solid black line represents the biexponential decay curve fitted to the data by SigmaPlot. C, Stimulation of $0.003 \mathrm{~Hz}$ elicited LFD with time constants $\tau_{1}=6 \mathrm{~min}$ and $\tau_{\|}=455$ min compared with $0.2 \mathrm{Hzstimulation}$ from $A$. Neurotransmitter release was stable at 0.0016 $\mathrm{Hz}$ stimulation. Measurements were normalized to the first EPSP. Each point in $\boldsymbol{B}$ and $\boldsymbol{C}$ is the average of six consecutive EPSPsinfour experiments \pm SE. Solid black lines represent the biexponential decay curve for the $\operatorname{data}(0.2 \mathrm{~Hz}, 0.003 \mathrm{~Hz})$. corded from the axon are reflected exactly in changes in terminal excitability.

\section{Phosphorylation and LFD}

Previous work showed that drugs that affect kinases and phosphatases modulate Crustacean synaptic transmission. For instance, Swain et al. (1991) showed that inhibition of phosphatases with OA greatly enhanced transmitter release at synapses of the crayfish claw-opener muscle. We hypothesized that LFD is caused by a reduction in phosphorylation of key proteins. The quantity of a particular phosphoprotein is governed by the relative rates of phosphorylation and dephosphorylation. The hypothesis predicts that decreases in the net rate of phosphorylation will increase the rate of LFD, whereas increases in the net rate will reverse or prevent LFD. To test the hypothesis that LFD depends on a decline in the quantity of critical phosphoproteins involved in transmitter release, we applied several regulators of phosphorylation and dephosphorylation and analyzed their effects on LFD.

\section{Kinase inhibitor accelerates phase II of LFD}

When the broad-spectrum kinase inhibitor staurosporine (10 $\mu \mathrm{M})$ was applied after $30 \mathrm{~min}$ of control stimulation, there was a small decrease in transmitter release $(n=4)$ (Fig. $3 A)$. When the same concentration of staurosporine was applied $10 \mathrm{~min}$ before stimulation, only phase II of LFD was increased $\left(\tau_{\mathrm{II} \text { (staurosporine) }}=\right.$ $\left.71 \mathrm{~min} ; \tau_{\mathrm{II}(\mathrm{no} \text { drug })}=105 \mathrm{~min} ; n=4\right)$ (Fig. $3 B$ ). Compared with control experiments without drug, staurosporine applied for 10 min before stimulation did not reduce the amplitude of the first EPSP; its effects therefore require nerve activity to be detectable. No significant effect on presynaptic action potential parameters was observed $(n=3)$.

\section{Inhibition of protein kinase $\mathrm{A}$ or protein kinase $\mathrm{C}$ accelerates LFD}

cAMP-dependent protein kinases A (PKA) and protein kinase $\mathrm{C}$ (PKC) were shown to be involved in LTF at crayfish neuromuscular junction (Atwood et al., 1989; Dixon and Atwood, 1989a) and in neuropeptide-induced potentiation (Friedrich et al., 1998). To examine the role of PKA, we applied the inhibitor Rp-cAMPS $(300 \mu \mathrm{M})$, which binds to the regulatory subunit of PKA (Dostmann et al., 1990) 10 min before $0.2 \mathrm{~Hz}$ stimulation. Rp-cAMPS accentuated the depression during phase II without affecting phase I $\left(\tau_{\mathrm{I}(\text { control })}=3.9 \mathrm{~min} ; \tau_{\mathrm{I}(\mathrm{Rp} \text {-cAMPS })}=4.1 \mathrm{~min}\right.$; $\left.\tau_{\mathrm{II}(\text { control })}=195 \mathrm{~min} ; \tau_{\mathrm{II}(\mathrm{Rp} \text {-cAMPS })}=153 \mathrm{~min} ; n=3\right)$. No significant effect on presynaptic action potential parameters was observed $(n=3)$. Thus, substrates for PKA may be involved in phase II of LFD but not phase I (Fig. 3C). An inhibitor of PKC, GF $(10 \mu \mathrm{M})$, applied after $30 \mathrm{~min}$ of stimulation at $0.2 \mathrm{~Hz}$ accelerated depression $(n=3)$ (Fig. $3 D)$. GF treatment had no significant effect on presynaptic action potential parameters $(n=3)$.

Control experiments to investigate possible activityindependent effects of these drugs were performed with stimulation at $0.0016 \mathrm{~Hz}$ to allow assay of transmitter release without significant depression. When applied for $70 \mathrm{~min}$, neither RpcAMPS (Fig. 3E) nor GF (Fig. 3F) showed progressive effects, but LFD $(0.2 \mathrm{~Hz})$ still occurred after this long preincubation. Therefore, time-dependent effects of these drugs were not a problem in the experiments shown in Figure 3, $C$ and $D$.

\section{Kinase stimulation inhibits LFD}

The hypothesis also predicts that increasing the critical phosphoproteins (either by accelerating kinases or inhibiting phosphatases) will reverse LFD. Therefore, we attempted to determine 
whether LFD could be blocked or inhibited by accelerating kinase activity. When PKC was stimulated with $100 \mu \mathrm{M}$ PMA, added after $30 \mathrm{~min}$ of depression, there was partial recovery from depression $(n=3)$ (Fig. $4 A$ ), suggesting that a complete recovery from depression might also require an increased activity of other kinases and/or inhibition of phosphatases. No significant effect on presynaptic action potential parameters was observed $(n=2)$. In control experiments, inactive 4- $\alpha$-PMA did not affect LFD $(n=2$; data not shown).

Because phorbol esters can enhance transmitter release by acting on Munc-13 (Betz et al., 1998), we applied PMA with $\mathrm{GF}$, an inhibitor of PKC, to distinguish phorbol-mediated effects on PKC from those on Munc-13. An example experiment is shown in Figure $4 B$ in which PMA $(100 \mu \mathrm{M})$ was applied $5 \mathrm{~min}$ after starting the stimulation and caused a partial recovery from phase II of depression. No significant effect on presynaptic action potential parameters was observed $(n=3)$. Once the increase in EPSP amplitude stabilized, GF was applied, and this reversed the effect of PMA and accelerated depression of neurotransmitter release $(n=2)$. Because PMA ceased to work in the presence of GF, we conclude that effects of PMA on LFD were attributable to effects on PKC.

Activation of PKA with Sp-cAMPS (100 $\mu \mathrm{M})$, a membrane-permeant cAMP analog (Dostmann et al., 1990), concomitantly with the stimulation affected only phase II $\left(\tau_{\mathrm{I}(\text { control })}=3.9 \mathrm{~min} ; \tau_{\mathrm{I}(\mathrm{Sp}-\mathrm{cAMPS})}=3.1 \mathrm{~min}\right.$; $\tau_{\mathrm{II}(\mathrm{control})}=195 \mathrm{~min} ; \tau_{\mathrm{II}(\mathrm{Sp}-\mathrm{cAMPS})}=516$ min; $n=4$ ) (Fig. 4C). No significant effect on presynaptic action potential parameters was observed $(n=2)$. When Sp-cAMPS $(100 \mu \mathrm{M})$ was added after $30 \mathrm{~min}$ of stimulation at $0.2 \mathrm{~Hz}$, there was a small recovery from depression $(n=4)$ (Fig. $4 D)$. No significant effect on presynaptic action potential parameters was observed $(n=4)$.

These results suggest that depression can be ameliorated to some extent by the additional activity of at least two kinases. The similarity of effects caused by activation of either PKC or PKA might suggest that they act on the same substrate. To test this hypothesis, in preliminary experiments, we added both PMA and Sp-cAMPS after $30 \mathrm{~min}$ of stimulation $(n=2)$ (data not shown) but found no additive effect as if both enzymes worked on the same substrate. No significant effect on presynaptic action potential parameters was observed $(n=2)$. An incomplete recovery caused by activation of PKA and PKC may indicate that during LFD, protein phosphatase activation also occurs. We next tested the hypothesis that phosphatases are involved in depression.

\section{Protein phosphatase inhibitor okadaic acid causes recovery} from depression

We inhibited phosphatases with a broad-spectrum phosphatase inhibitor okadaic acid. OA was applied at various times to deter-

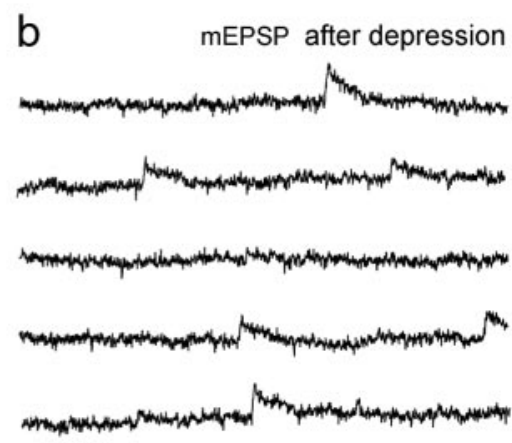

$60 \mathrm{msec}$

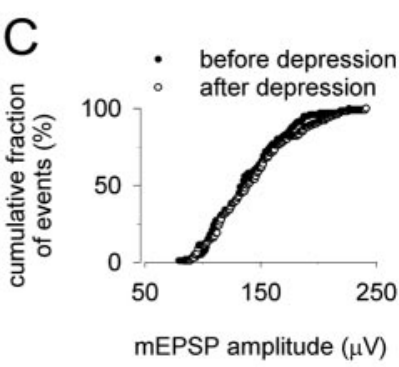

mEPSP amplitude $(\mu \mathrm{V})$

b

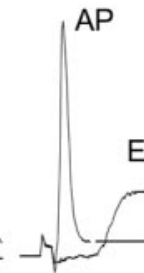

EPSP

Figure 2. LFD is a presynaptic phenomenon. $\boldsymbol{A}$, Example of $\mathrm{mEPSP}$ recordings before $(\boldsymbol{a})$ and after $(\boldsymbol{b})$ LFD. $\boldsymbol{B}$, Frequency distribution of release. A total of 96 events were analyzed in each distribution. An increase in mEPSP frequency was obtained by graded axonal depolardistributions before and after LFD $(p>0.1 ; n=3)$. D. Representative simultaneous recordings of presynaptic AP and EPSP at 0 min $(\boldsymbol{a})$ and $75 \mathrm{~min}(\boldsymbol{b})$ of depression elicited by $0.2 \mathrm{~Hz}$ stimulation shows that the phasic axon action potential was affected little during depression, although the afterdepolarization was increased $(n=5)$.

mine whether phosphatase activity continues during LFD. When $\mathrm{OA}(10 \mu \mathrm{M})$ was applied after $5 \mathrm{~min}$ of stimulation at $0.2 \mathrm{~Hz}$, the EPSP increased and reached stability near initial levels, although there was considerable variability between preparations in the amplitude at which stability was achieved (Fig. 5A). Application of OA $(10 \mu \mathrm{M})$ after $30 \mathrm{~min}$ of stimulation enhanced markedly the EPSP $(n=4)$ (Fig. $5 B)$. Application of OA after $90 \mathrm{~min}$ of stimulation also caused recovery from depression (Fig. 5C) and did not affect significantly the presynaptic action potential parameters $(n=3)$. When OA was applied $10 \mathrm{~min}$ before stimulation, a decline in the EPSP still occurred when stimulation began, consistent with phase I of LFD, but thereafter transmitter release was relatively stable (Fig. 5D). The lower level of stabilization of transmission, compared with the levels obtained when OA was added after the initiation of stimulation, may indicate that some dephosphorylation of proteins by OA-sensitive phosphatase that occurs before stimulation might be required for an increased effect of OA treatment after stimulation. There was no significant 
A
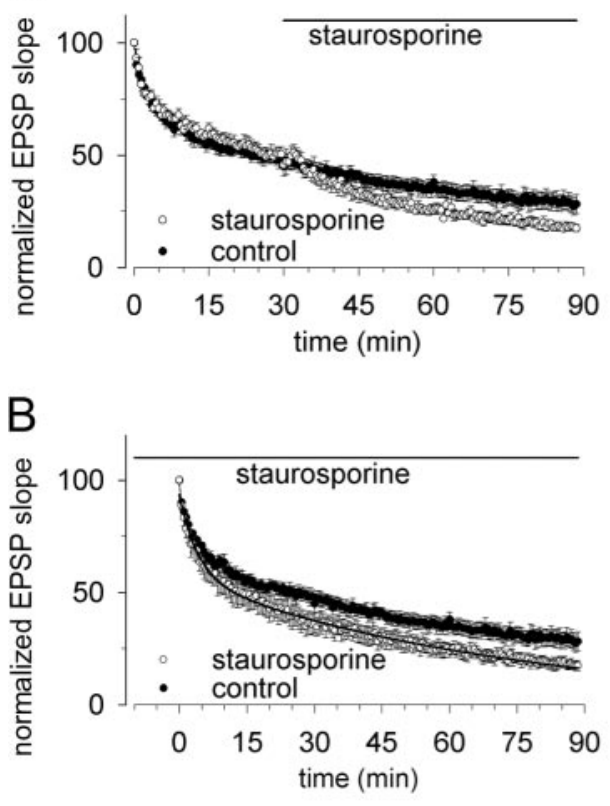

E

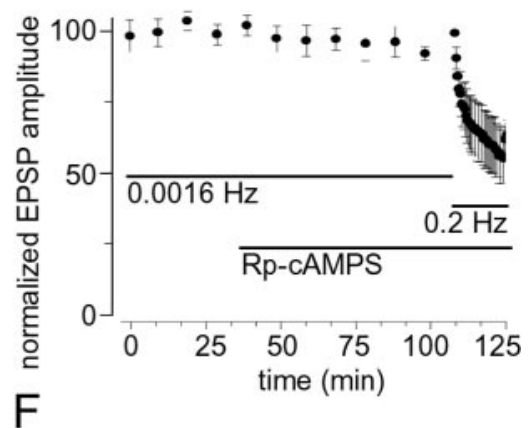

$\mathrm{F}$

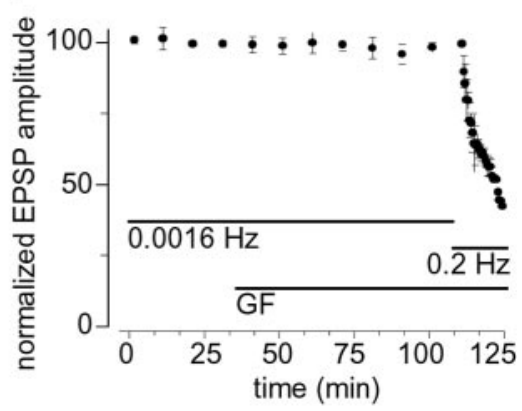

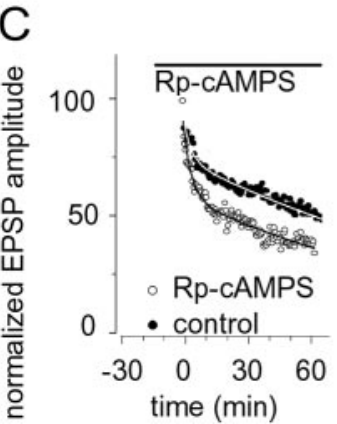

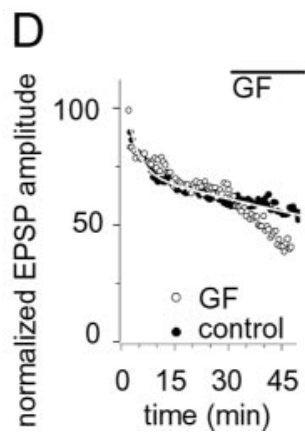

Figure 3. Kinase inhibitors increase depression. $\boldsymbol{A}$, Staurosporine $(10 \mu \mathrm{M})$ applied after $30 \mathrm{~min}$ of $0.2 \mathrm{~Hz}$ stimulation caused a small decrease in transmitter release (EPSP slope measurement) $(n=4)$. $\boldsymbol{B}$, Staurosporine (10 $\mu \mathrm{m})$ applied 10 min before the start of $0.2 \mathrm{~Hz}$ stimulation increased only phase Il of LFD (EPSP slope measurement) $(n=4)$. The data were fit by a biexponential decay curve (solid black line in each curve) with time constants $\tau_{1}=4 \mathrm{~min}$ and $\tau_{\|}=71 \mathrm{~min}$. Controls were similar recordings without drug application ( $\tau_{1}=4 \mathrm{~min} ; \tau_{\|}=105 \mathrm{~min} ; n=4$ ). Each point is the average of six consecutive EPSPs in four experiments \pm SE. Bars indicate the presence of staurosporine in the bathing solution. C, Rp-CAMPS (300 $\mu \mathrm{m}$ ) added $10 \mathrm{~min}$ before the $0.2 \mathrm{~Hz}$ stimulation caused a slight accentuation of depression $\left(\tau_{1}=4.1 \mathrm{~min} ; \tau_{\|}=153 \mathrm{~min} ; n=3\right)$ compared with control experiments $\left(\tau_{1}=3.9 \mathrm{~min} ; \tau_{\|}=195 \mathrm{~min} ; n=3\right) \pm$ SE. Each point is the average of six consecutive EPSPs in three experiments. Measurements were normalized to the maximum amplitude of the first EPSP. The bar indicates the presence of Rp-cAMPS in the bathing solution. Solid black and white lines represent the biexponential decay curves for the data. D, GF (10 $\mu \mathrm{m})$ applied after 30 min of stimulation at $0.2 \mathrm{~Hz}$ accelerated depression $(n=3)$. Each point is the average of six consecutive EPSPs in three experiments. Measurements were normalized to the maximum amplitude of the first EPSP. The bar indicates the presence of GF in the bathing solution. The solid white line represents the biexponential decay curves for the data. $\boldsymbol{E}$, Control experiment for the nonactivity-dependent effect of Rp-CAMPS. After $40 \mathrm{~min}$ of stimulation at $0.0016 \mathrm{~Hz}, \mathrm{Rp}$-CAMPS was added, transmitter release was monitored for $70 \mathrm{~min}$, and then the stimulation frequency was increased to $0.2 \mathrm{~Hz}(n=3)$. The bar indicates the presence of Rp-cAMPS in the bathing solution. At $0.2 \mathrm{~Hz}$, each point is the average of six consecutive stimuli in three experiments $\pm \mathrm{SE}$. $\boldsymbol{F}$, Control experiment for the nonactivity-dependent effect of GF. After 40 min of stimulation at $0.0016 \mathrm{~Hz}$, GF was added, transmitter release was monitored for $70 \mathrm{~min}$, and the stimulation frequency was increased to $0.2 \mathrm{~Hz}(n=3)$. The bar indicates the presence of GF in the bathing solution. At $0.2 \mathrm{~Hz}$, each point is the average of six consecutive stimuli in three experiments $\pm \mathrm{SE}$.

difference in the distribution of mEPSP amplitude before and after 10 min of stimulating the phasic axon in the presence of OA (data not shown).

To examine the possibility that apparent recovery from depression by OA was simply because of a gradual effect that was not stimulus dependent, we applied OA with extremely lowfrequency stimulation $(0.0016 \mathrm{~Hz})$ that did not cause depression. This allowed us to detect nonstimulus-dependent effects and to determine their time course. After $40 \mathrm{~min}$ of control recording,
OA was applied for $70 \mathrm{~min}$, and transmitter release increased $(\sim 33 \%)$ to a maximum within 10 min (Fig. $5 E$ ); when the stimulation frequency was then increased to $0.2 \mathrm{~Hz}$, phase I of depression occurred, but phase II did not. These results indicate that nonstimulus-dependent effects of OA would have reached a maximum early in the recovery shown in Figure $5 A-D$ and thus were not a major factor in recovery from depression. These results also indicate that nonstimulus-dependent effects of OA were not a major factor in preventing the appearance of phase II of depression. Because the treatments with staurosporine, Rp-cAMPS, Sp-cAMPS, and OA affected only phase II, this phase may involve different enzymes and substrates than phase I.

\section{Coapplication of kinase and phosphatase inhibitors prevents phase II of LFD}

To determine whether the prevention and recovery from depression caused by $\mathrm{OA}$ depends on ongoing phosphorylation, we applied kinase inhibitor and phosphatase inhibitor together. Two scenarios may explain the observation that staurosporine and Rp-cAMPS decreased EPSP amplitude, whereas OA increased EPSP amplitude: (1) the drugs affect the mechanism of LFD and (2) the drugs do not have an effect on LFD but affect a parallel phosphorylation-dependent pathway that also modulates transmitter release. If the second scenario is correct, coapplication of the drugs will prevent this pathway, and LFD will continue to be observed as an ongoing decline in transmitter release. If the first scenario is correct, then coapplication of staurosporine and OA or Rp-cAMPS and OA will prevent both ongoing phosphorylation and dephosphorylation of the substrate critical in LFD, preventing LFD and thus stabilizing transmitter release.

To test this hypothesis, we applied OA $(10 \mu \mathrm{M})$ after $30 \mathrm{~min}$ of control stimulation in the presence of $10 \mu \mathrm{M}$ staurosporine (Fig. $6 A$ ). When staurosporine and OA were present together in the bathing solution, transmitter release was stable. In another set of experiments, drugs were coapplied $15 \mathrm{~min}$ before stimulating (Fig. 6B). Consistent with our previous results, application of both drugs before stimulation had little effect on phase I $\left(\tau_{\text {I(control) }}=4 \mathrm{~min} ; \tau_{\text {I(stau }+\mathrm{OA})}=5 \mathrm{~min}\right)$ of LFD but almost completely abolished phase II $\left(\tau_{\text {III controll })}=105 \mathrm{~min}\right.$; $\left.\tau_{\mathrm{II}(\mathrm{stau}+\mathrm{OA})}=5000 \mathrm{~min}\right)$. Similar results were obtained by coapplying the drugs $30 \mathrm{~min}$ before stimulating at $0.2 \mathrm{~Hz}$ (Fig. 6C).

When the PKA inhibitors Rp-cAMPS $(300 \mu \mathrm{M})$ and OA (10 $\mu \mathrm{M}$ ) were applied $15 \mathrm{~min}$ before stimulation, transmitter release was maintained at a constant level except for the development of phase I ( $\left.\tau_{\mathrm{I}}=6 \mathrm{~min} ; \tau_{\mathrm{II}}=9.4^{\star} 10^{12} \mathrm{~min} ; n=4\right)$ (Fig. $\left.6 D\right)$. No 
significant effect on the presynaptic axon action potential parameters was observed $(n=2)$. When OA was applied after 30 min of stimulation in the presence of RpcAMPS $(300 \mu \mathrm{M})(n=5)$, there was a slight increase in transmitter release followed by maintenance of transmitter release at a relatively constant level (Fig. $6 E$ ). No significant effect on presynaptic action potential parameters was observed $(n=$ $3)$. Thus, maintenance of transmitter release in the presence of OA does not require staurosporine-sensitive kinases, including PKA. When OA was applied alone, there was always an increase in transmitter release once LFD had developed. However, when OA was applied after staurosporine, there was no increase. Therefore, the increase seen with $\mathrm{OA}$ required the action of kinases that, during or after phase I, phosphorylate a protein that is then dephosphorylated by OA-sensitive phosphatase during phase II.

These results demonstrate that phase II of LFD depends in part on a decline in phosphorylated substrate produced by staurosporine-sensitive kinases and that dephosphorylation of phosphosubstrate requires the activity of phosphatases sensitive to OA.

\section{Calcineurin blockers inhibit both phases of LFD}

The results obtained with OA implicate protein phosphatase 1 and protein phosphatase 2A in phase II of LFD. We next asked whether $\mathrm{Ca}^{2+}$-calmodulin-activated Ser-Thr protein phosphatase $2 \mathrm{~B}$ (calcineurin) is involved in LFD. To determine the involvement of calcineurin in LFD, we applied a specific inhibitor, FK-506 $(40 \mu \mathrm{M})$, concomitantly with stimulation. This treatment blocked the depression and caused a sustained increase of EPSP amplitude $(n=5)$ (Fig. $7 A)$, suggesting that calcineurin functions in phase I of LFD. No significant effect on presynaptic action potential parameters was observed $(n=4)$.

As a negative control for FK-506, we used rapamycin $(40 \mu \mathrm{M})$, an immunosuppressant that binds to FK-506 binding proteins (FKBPs) such as FKBP12 but does not affect the calcineurin activity (Kunz and Hall, 1993). Rapamycin applied concomitantly with stimulation had no effect on phases I or II of LFD (Fig. 7B) and did not affect significantly the axon action potential parameters $(p>0.05 ; n=3)$. When applied after LFD, rapamycin did not cause recovery from depression ( $n=2$; data not shown). When tested at a nondepressing frequency $(0.0016 \mathrm{~Hz}), \mathrm{FK}-506$ caused a small increase in transmitter release that stabilized within $10 \mathrm{~min}(n=3)$ (Fig. $7 C)$, showing that time-dependent effects are not a major factor in blockade of LFD, as shown in Figure $7 A$. Subsequent stimulation at $0.2 \mathrm{~Hz}$, which normally causes LFD, now caused facilitation.

Because FK-506 inhibits calcineurin indirectly via interaction with FKBPs, we tested a peptide inhibitor that interacts directly with calcineurin (Beaumont et al., 2001; Terada et al., 2003). A portion of the calcineurin autoinhibitory domain (catalytic A subunit C-terminal residues 472-485) coupled to 11 arginines is a convenient inhibitor. When this cell-permeant peptide $(50 \mu \mathrm{M})$ was applied concomitantly $(n=4)$ (Fig. $7 D)$ or 30 min before starting the stimulation $(n=5)$ (data not shown), both phases of LFD were blocked and transmitter release gradually increased when stimulation began. No significant effect on presynaptic action potential parameters was observed when the peptide was applied concomitantly with the stimulation $(n=3)$. When the peptide was applied $10 \mathrm{~min}$ after starting the stimulation, there was recovery from depression, although the level of recovery varied between experiments $(n=4)$ (data not shown). When the peptide was applied after $50 \mathrm{~min}$ of control stimulation at 0.0016 $\mathrm{Hz}$, there was a small increase in release that reached a maximum within $20 \mathrm{~min}(n=3)$ (Fig. $7 E$ ). Subsequent stimulation at $0.2 \mathrm{~Hz}$ caused facilitation of transmitter release rather than depression. Both treatments abolished phases I and II of LFD. Effects of the calcineurin blockers to increase transmitter release were at a maximum before depression was tested; when depressing stimuli were given, there was facilitation instead of depression, suggesting that when calcineurin is inactive, LFD is not expressed. Thus, inhibition of calcineurin activity blocked the development of both phases of LFD, whereas OA blocked only the late phase. Therefore, these drugs, at the concentrations used, identify different sets of phosphatase activities.

To determine whether calcineurin activation persists during phase II of LFD, we applied FK-506 (40 $\mu \mathrm{M})$ after $30 \mathrm{~min}$ of $0.2 \mathrm{~Hz}$ stimulation $(n=3)$ (Fig. $7 F)$. Phase II of LFD was reversed with a large increase in EPSP amplitude but no significant effect on the presynaptic action potential parameters $(n=3)$. This suggests that inhibiting their dephosphorylation probably increased the amount of phosphoproteins available to function during neurotransmitter release. 

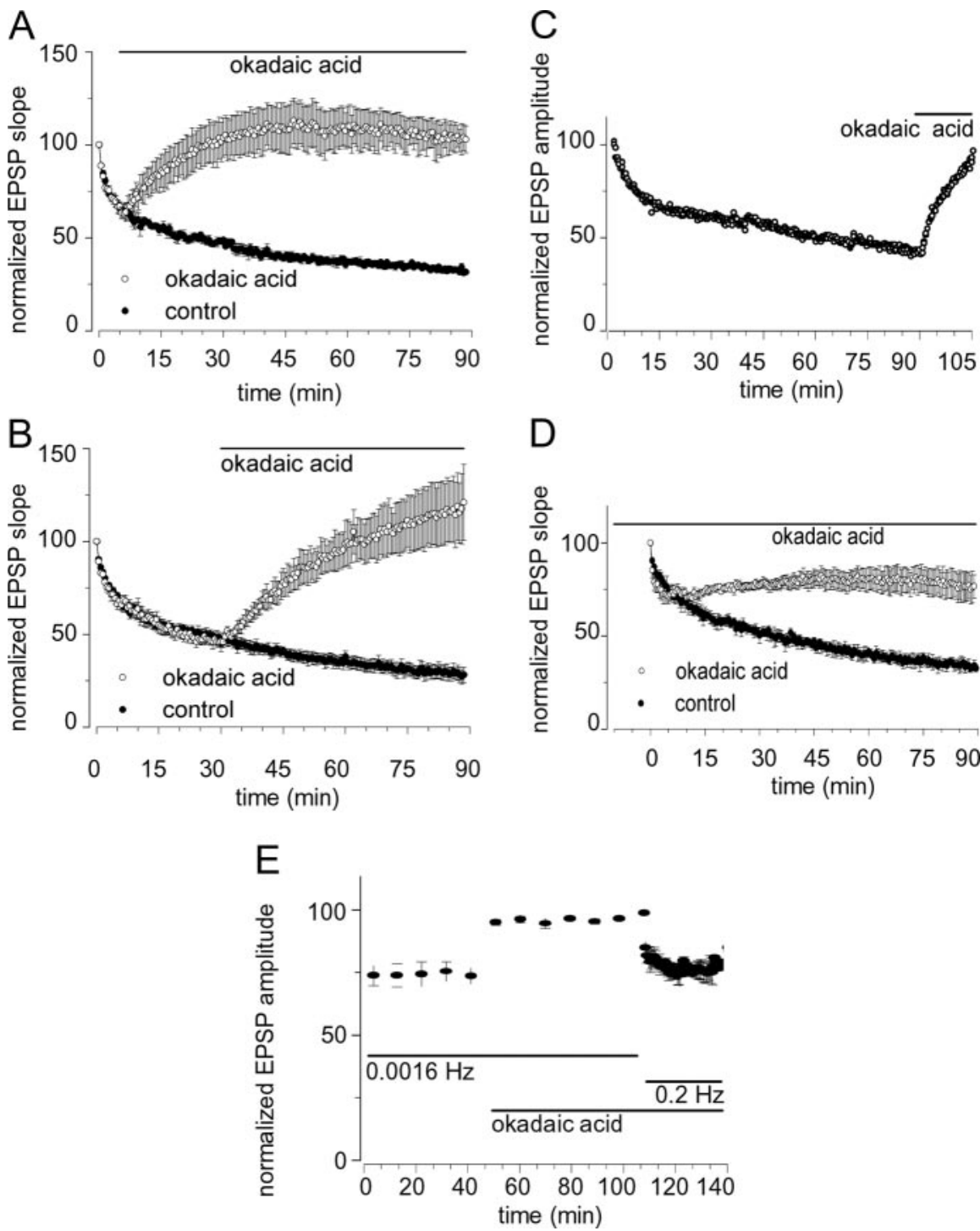

Figure 5. Okadaic acid causes recovery from depression. $\boldsymbol{A}$, Okadaic acid (10 $\mu \mathrm{m}$ ) applied $5 \mathrm{~min}$ after starting the $0.2 \mathrm{~Hz}$ stimulation increased transmitter release and reached stability near initial levels. $\boldsymbol{B}$, After $30 \mathrm{~min}$ of stimulation at $0.2 \mathrm{~Hz}$ application of okadaic acid (10 $\mu \mathrm{m}$ ) reversed the depression. C, Example experiment showing that application of okadaic acid (10 $\mu \mathrm{m}) 90 \mathrm{~min}$ after stimulation increased transmitter release to near initial levels. $\boldsymbol{D}, 0$ kadaic acid (10 $\mu \mathrm{m})$ bath applied 10 min before the beginning the stimulation prevented the occurrence of phase II of LFD. Controls were similar recordings without drug application $(n=4)$ ). Each point is the average of six consecutive EPSPs in four experiments \pm SE. Bars indicate the presence of okadaic acid in the bathing solution. $\boldsymbol{E}, 0$ kadaic acid has nonactivity-dependent effects. After 40 min of stimulation at $0.0016 \mathrm{~Hz}$, $0 A$ was applied for $70 \mathrm{~min}$. Transmitter release increased but stabilized within $10 \mathrm{~min}$. When the stimulation frequency was increased subsequently to $0.2 \mathrm{~Hz}$, phase I of LFD occurred, but phase II did not. At $0.2 \mathrm{~Hz}$, each point is the average of six consecutive stimuli. The data are averaged from three experiments \pm SE.

\section{Calcineurin in crayfish synapses.}

Immunostaining with a rabbit polyclonal antibody against the regulatory subunit of mammalian calcineurin $\mathrm{B} \alpha$ showed immunoreactivity both in the thin, filiform nerve endings of phasic neurons and in the larger tonic terminals with more prominent varicosities (Fig. $8 A b, A c$ ). Syntaxin staining as a nerve terminal marker is shown in Figure 8, $A a$ and $A c$. Similar calcineurin immunoreactivity was observed in preparations not stained for syntaxin. There was no immunoreactivity in preparations in which only the secondary antibody was applied.

Western blot analysis showed that anticalcineurin $\mathrm{B} \alpha$ antibody recognizes a single protein band of $\sim 18 \mathrm{kDa}$ in both crayfish nerve cord (Fig. $8 \mathrm{Ba}$, lane C) and Drosophila larvae (Fig. $8 \mathrm{Ba}$, lane $\mathrm{D})$. This is consistent with the predicted molecular weight
(MW) of $19.3 \mathrm{kDa}$ for Drosophila calcineurin reported by Guerini et al. (1992) and indicates that this antibody detects the presence of crayfish calcineurin. The antibody for the catalytic subunit $\mathrm{A} \alpha$ recognized a protein of $\sim 70 \mathrm{kDa}$ in both crayfish (Fig. $8 \mathrm{Bb}$, lane C) and Drosophila (Fig. $9 \mathrm{Bb}$, lane $\mathrm{D})$, and this is comparable with the predicted MW of $64.6 \mathrm{kDa}$ (Guerini et al., 1992). The similarity of the crayfish protein to Drosophila protein indicates that the immunostaining in synaptic areas likely represents calcineurin. Calcineurin $\mathrm{B} \alpha$ and syntaxin are also present in neuronal cell bodies from crayfish nerve cord (Fig. 8Ad-Af) and Drosophila CNS in both brain hemisphere and ventral ganglion (Fig. $8 A g-A i)$. Syntaxin is located at crayfish neuropil (Fig. 8Ad,Af) and at the boundary of Drosophila neuronal cell bodies (arrowheads), presumably plasma membrane (Fig. 8Ag,Ai), whereas calcineurin is located within the neuronal cell bodies (Fig. 8Ae,Af,Ah,Ai, arrowheads). The immunostaining indicates that the calcineurin antibodies work similarly in both species, and the detection of similar single-protein bands in Drosophila in which the MW of calcineurin is known and in crayfish in which it is unknown, verifies that the immunostaining at the crayfish neuromuscular junction is indeed calcineurin.

\section{Recovery from LFD}

If LFD is caused by stimulation-dependent dephosphorylation, there should be a stimulation frequency at which LFD does not occur and at which there is recovery from LFD; at this frequency, rates of phosphorylation and dephosphorylation would be similar. There was less LFD at $0.003 \mathrm{~Hz}$ than at $0.2 \mathrm{~Hz}$ (Fig. $1 C$ ), and at $0.0016 \mathrm{~Hz}$, little depression was observed in this series of experiments $(n=3)$ (Fig. $9 A)$. However, LFD could be elicited after $110 \mathrm{~min}$ of stimulation at $0.0016 \mathrm{~Hz}(n=$ 3) (Fig. 9B)

Next, we studied recovery from depression by reducing the stimulation frequency from $0.2 \mathrm{~Hz}$ after depression was expressed. After $30 \mathrm{~min}$ of LFD at $0.2 \mathrm{~Hz}$, the frequency was reduced to $0.003 \mathrm{~Hz}$ for $30 \mathrm{~min}$, and there was partial recovery $(n=3)$ (data not shown). However, after 10 $\min (n=3)$ or $30 \min (n=3)$ of LFD $(0.2 \mathrm{~Hz})$, reduction of stimulation frequency to $0.0016 \mathrm{~Hz}$ caused recovery from LFD (Fig. 9C,D), and even after $60 \mathrm{~min}$ of LFD, recovery could be observed $(n=2)$ (data not shown).

To test the hypothesis that recovery from LFD requires kinase activity, we applied staurosporine during recovery $(0.0016 \mathrm{~Hz})$ after $10 \mathrm{~min}(n=3)$ or $30 \mathrm{~min}(n=3)$ of LFD $(0.2 \mathrm{~Hz})$ (Fig. $9 E, F)$. In some experiments, we delayed application of staurosporine until a single EPSP had been recorded at $0.0016 \mathrm{~Hz}$. This single EPSP was larger than the preceding EPSP, showing that the 
recovery could occur before staurosporine was added (Fig. 9F). Staurosporine always blocked recovery from LFD.

\section{Discussion \\ LFD}

LFD at leg extensor phasic synapse depends on stimulation frequency and is comprised of two phases with time constants of 4 and $105 \mathrm{~min}$. We found no evidence for a postsynaptic mechanism involving loss of sensitivity to transmitter nor was LFD accompanied by changes in the presynaptic action potential sufficient to cause the loss of transmitter release. Availability of transmitter does not appear to be limited during LFD, because neither phase is sensitive to manipulations that reduced the quantity of transmitter released per stimulus at motor giant neuronal synapses (Zucker and Bruner, 1977).

\section{LFD and phosphorylation}

Protein kinase inhibitors staurosporine, Rp-cAMPS, and GF speed up depression, whereas phosphatase inhibitors (OA, FK506, calcineurin autoinhibitory peptide) and kinase activators (PMA and SpcAMPS) reverse depression. OA applied after 30 min of stimulation in the presence of staurosporine or Rp-cAMPS stabilizes transmitter release, suggesting that these drugs affect the mechanism of phase II of LFD. Together, this indicates that phase II of LFD is the result of a decline in phosphoprotein attributable to an increase in OA-sensitive phosphatase and calcineurin activity relative to PKA and PKC and possible additional staurosporine-sensitive kinases activities. Phase II, but not phase I, of LFD was blocked by OA. In contrast, inhibition of calcineurin blocked both phase I and phase II. Phase II of LFD may therefore involve substrates phosphorylated by PKA-, PKC-, and possibly other staurosporine-sensitive kinases and substrates that are dephosphorylated by phosphatases blocked by OA and calcineurin.

Phase I of LFD depends on phosphorylation by calcineurin. Our data do not explain why inhibition of calcineurin blocks both phases of LFD. We speculate that calcineurin may dephosphorylate proteins involved in exocytosis and that, only after they have been partially dephosphorylated, some of these proteins then become targets for phosphatases 1 and 2A. Another explanation could be that, in addition to its action on exocytosis proteins, calcineurin dephosphorylates inhibitor-1, which then no longer inhibits PP1 or other phosphatases sensitive to OA (Mulkey et al., 1994) (for review, see Colbran, 2004). In this scenario, there would be a sequential activation of calcineurin followed by removal of inhibition from other phosphatases. The block of recovery from depression by staurosporine indicates that recovery requires the activity of kinases that can rephosphorylate substrates once phosphatases are no longer turned on by stimulation.
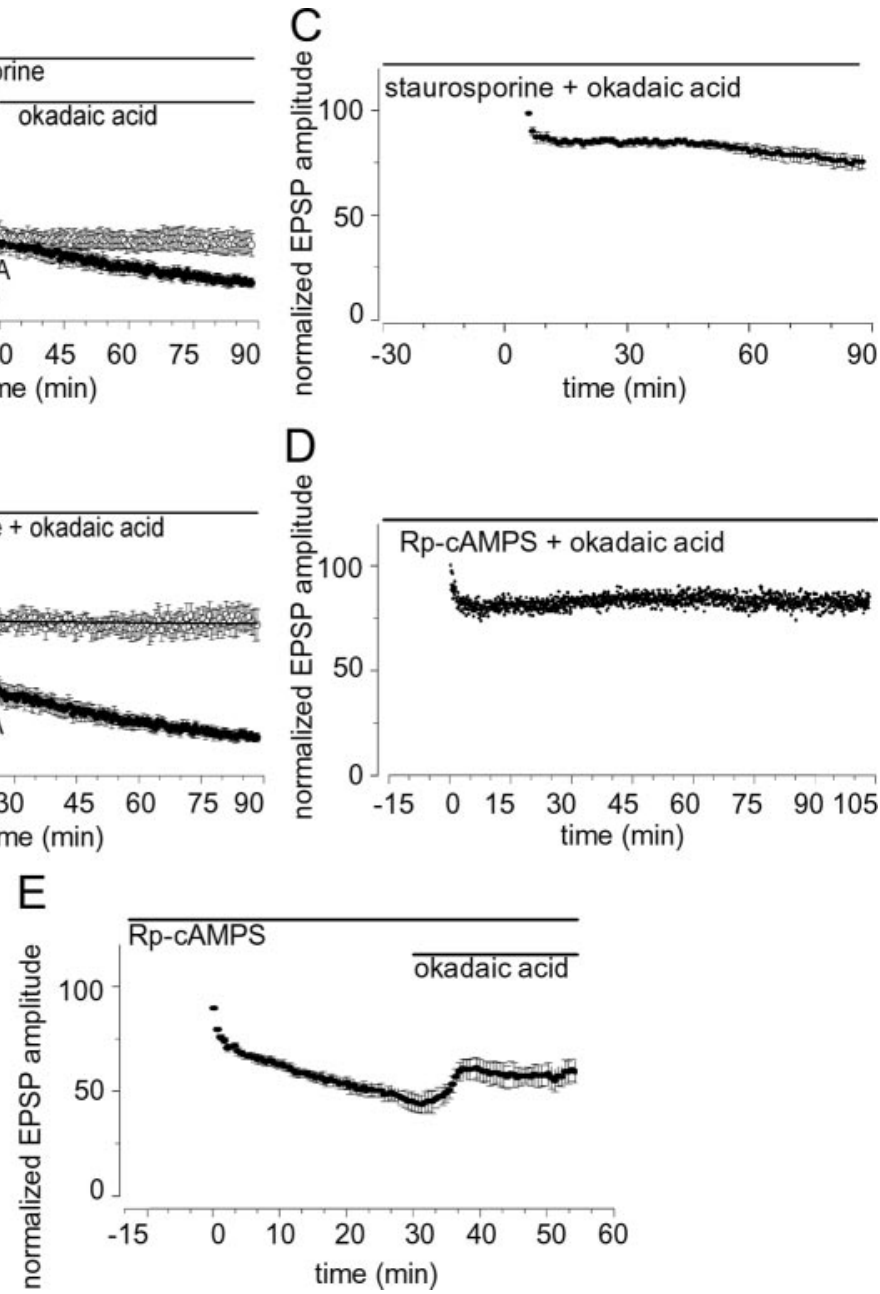

Figure 6. Coapplication of staurosporine and okadaic acid or Rp-CAMPS and okadaic acid stabilizes transmitter release and prevents phase II LFD. $A$, Staurosporine $(10 \mu \mathrm{m})$ was bath applied $10 \mathrm{~min}$ before stimulation. After $30 \mathrm{~min}$ of stimulation at $0.2 \mathrm{~Hz}$, okadaic acid $(10 \mu \mathrm{m}$ ) was applied (open circles; $n=4)$. The presence of staurosporine and okadaic acid in the bathing solution iminated. Control recordings at $0.2 \mathrm{~Hz}$ (closed circles; $n=4$ ) were performed in the presence of $10 \mu \mathrm{m}$ staurosporine $\left(\tau_{1}=4\right.$ 㱐 $=71 \mathrm{~min}$ ). The black line represents a biexponential decay curve for the data. Each point is the average of six consecutive ation at $0.2 \mathrm{~Hz}$. Each point is the average of six consecutive EPSPs in three experiments \pm SE. D, The PKA blocker 作 almost completely abolished phase II of LFD. $\boldsymbol{E}$, Rp-CAMPS $(300 \mu \mathrm{m})$ was added 15 min before stimulation. After 30 min of stimulation, $O A(10 \mu \mathrm{m})$ was added and caused a slight enhancement of transmitter release. Each point is the average of six consecutive EPSPs in five experiments \pm SE. Bars indicate the presence of drugs in the bathing solution.

The drugs we used had no detectable effect on the resting potential or action potential of the presynaptic axon, and it is therefore unlikely that their main targets are channels that are critical for electrogenesis. Our data are the first obtained from phasic axons, but several studies were done in tonic axons. For instance, in the tonic axons of crayfish leg-opener muscle excitatory synapses, dibutyryl cAMP, forskolin (an enhancer of cAMP production), phorbol ester 12-O-tetradecanoyl phorbol-13acetate, or Walsh inhibitor of PKA injected presynaptically have no effect on the action potential or membrane potential (Dixon and Atwood, 1989a,b). 5-HT, forskolin, and 8-Br-cAMP caused presynaptic depolarization of $\sim 10 \mathrm{mV}$ in crayfish opener muscle tonic excitatory axon branches (Dixon and Atwood, 1989b; Beaumont and Zucker, 2000) because of activation of $I_{\mathrm{h}}$ channels (Beaumont and Zucker, 2000). However, in chick ciliary- 
A

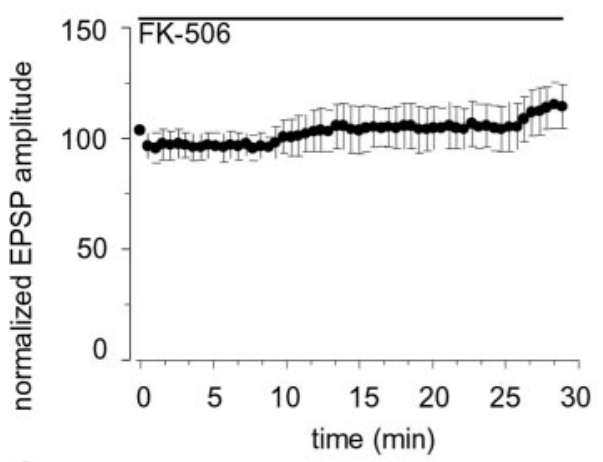

C

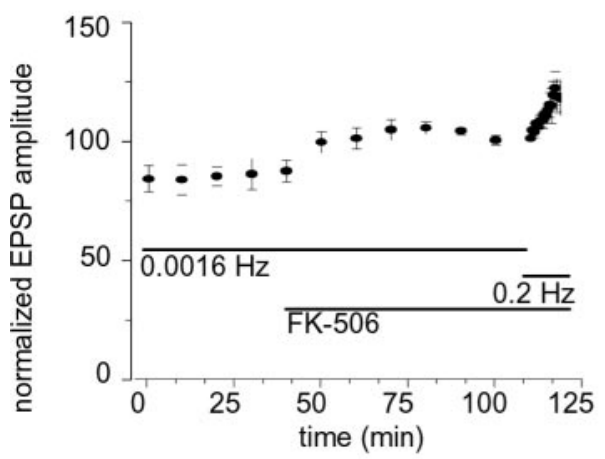

E

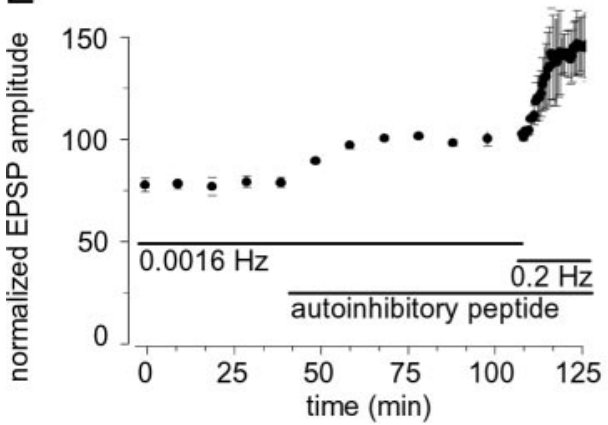

B

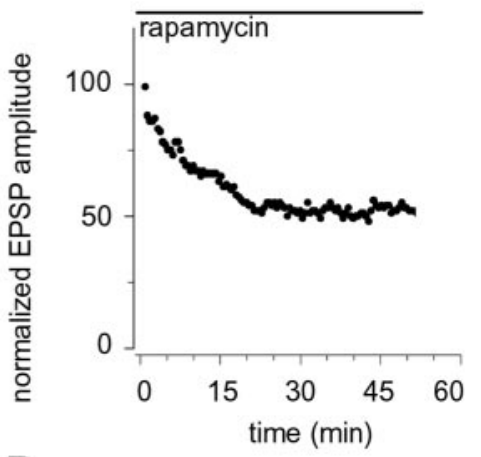

D

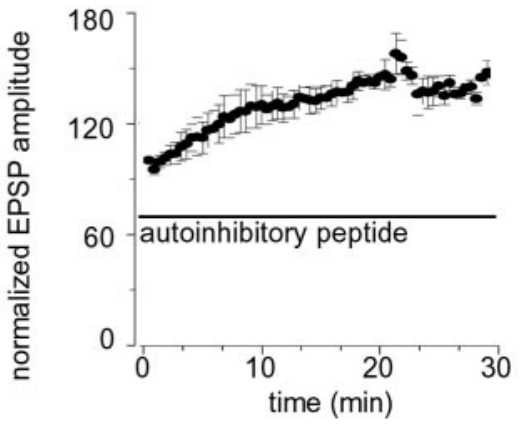

$\mathrm{F}$

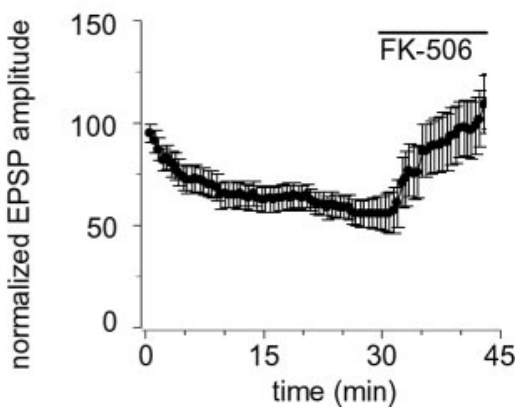

Figure 7. Inhibition of calcineurin abolished LFD. $A$, When added concomitantly with stimulation, FK-506 (40 $\mu \mathrm{m})$ inhibited depression and caused an increase of EPSP amplitude. Each point is the average of six consecutive EPSPs in five experiments \pm SE. $B$, Rapamycin $(40 \mu \mathrm{M})$ applied concomitantly with stimulation at $0.2 \mathrm{~Hz}$ had no effect on LFD $(n=3)$. C, In control experiments for nonactivity-dependent effects, FK-506 (40 $\mu \mathrm{m})$ was added after stimulation at $0.0016 \mathrm{~Hz}$ for $40 \mathrm{~min}$. Transmitter release increased slightly but stabilized within $10 \mathrm{~min}$. After $70 \mathrm{~min}$ in FK-506, the stimulation frequency was increased to $0.2 \mathrm{~Hz}$, but instead of LFD, there was facilitation of transmitter release $(n=3)$. $\boldsymbol{D}$, Permeant calcineurin autoinhibitory peptide $(50 \mu \mathrm{M})$ added concomitantly with stimulation inhibited depression and caused an increase in EPSP amplitude. Each point is the average of six consecutive EPSPs in four experiments \pm SE. E, Control experiment for nonactivity-dependent effects of calcineurin autoinhibitory peptide. When the peptide was added after stimulation at $0.0016 \mathrm{~Hz}$ for $40 \mathrm{~min}$, transmitter release increased slightly but stabilized within $16 \mathrm{~min}$. After 70 min of peptide application, stimulation at $0.2 \mathrm{~Hz}$ began, but instead of LFD, there was facilitation $(n=3)$. $\boldsymbol{F}$, FK-506 $(40 \mu \mathrm{M})$, applied after $30 \mathrm{~min}$ of $0.2 \mathrm{~Hz}$ stimulation, caused recovery from depression and a large increase in the amplitude of EPSPs. Each point is the average of six consecutive EPSP in three experiments \pm SE. Bars indicate the presence of drugs in the bathing solution.

myotube cultures, 8-Br-cAMPS had no effect on the presynaptic action potential (Dubinsky and Fischbach, 1990). In the chick ciliary ganglion, drugs that modulate PKC activity did not affect presynaptic $\mathrm{Ca}^{2+}$ (Yawo, 1999a,b). 5-HT increased resting $\left[\mathrm{Ca}^{2+}\right]_{\mathrm{i}}$ in some terminals of the crayfish opener muscle tonic excitatory axon, but in most there was no change (Delaney et al., 1991). At the tonic-like crayfish opener muscle inhibitory synapses, okadaic acid accelerates transmitter release, but the effect is not attributable to increased $\mathrm{Ca}^{2+}$ influx (Lin and $\mathrm{Fu}, 2005$ ). Although LFD and our drug effects were not accompanied by changes in resting potential or action potentials in presynaptic axons, it is possible that in our experiments, there were changes in these parameters at synaptic boutons or in local $\mathrm{Ca}^{2+}$ signals at active zones.

\section{Phasic and tonic synapses}

The data suggest that in phasic synapses, proteins involved in synaptic transmission are normally in a phosphorylated state before stimulation and must remain phosphorylated, or otherwise, depression occurs. PKA, PKC, and other kinases may maintain a basal level of phosphorylated substrate at crayfish phasic synapses. For instance, another phasic synapse, the squid giant synapse, depresses easily and appears to have high-PKA activity and PKA substrates maintained in a highly phosphorylated state (Hilfiker et al., 2001). When we applied OA to phasic synapses, transmitter release increased by $\sim 33 \%$ (Fig. $5 E$ ), but at tonic excitor synapses on the crayfish leg-opener muscle, OA caused an increase of 300\% (Swain et al., 1991). This observation may indicate that in both phasic and tonic synapses, transmitter release is controlled by phosphorylation of critical substrates; however, under normal conditions, more of these are phosphorylated in phasic synapses than in tonic synapses.

Although bulk cytoplasmic $\mathrm{Ca}^{2+}$ signals in phasic terminals are twofold to threefold larger than in tonic terminals, when these signals were normalized to the number of active zones and terminal volume, it was concluded that the $\mathrm{Ca}^{2+}$ signal at individual active zones would be similar in phasic and tonic synapses (Msghina et al., 1999). Because our immunocytochemistry shows calcineurin in both the phasic and tonic terminals of the leg extensor muscle, it seems that both terminals should undergo LFD. However, the larger cytoplasmic $\mathrm{Ca}^{2+}$ signal in phasic terminals may activate calcineurin there, whereas the smaller $\mathrm{Ca}^{2+}$ signals in tonic terminals may be inadequate. Therefore, depression may not occur in tonic terminals because of an inadequate $\left[\mathrm{Ca}^{2+}\right]_{\mathrm{i}}$ to stimulate calcineurin. When quantal content of tonic terminals was increased by application of $\mathrm{Cs}^{2+}$ to cause broadening of the presynaptic action potential, there was depression (Millar et al., 2002), but it is unknown whether this involved calcineurin. In contrast, LTF at tonic synapses of the crayfish opener muscle produced by stimulation at $20 \mathrm{~Hz}$ for $10 \mathrm{~min}$ was blocked by inhibition of calcineurin. In this case, calcineurin apparently participates in regulation of local protein synthesis involved in LTF (Beaumont et al., 2001). Protein synthesis is unlikely to be an essential component of LFD, because rapamycin, a known inhibitor of protein synthesis, had no effect (Fig. 7B), although it blocked LTF (Beaumont et al., 2001). 
A

\section{Syntaxin Calcineurin B Merged}
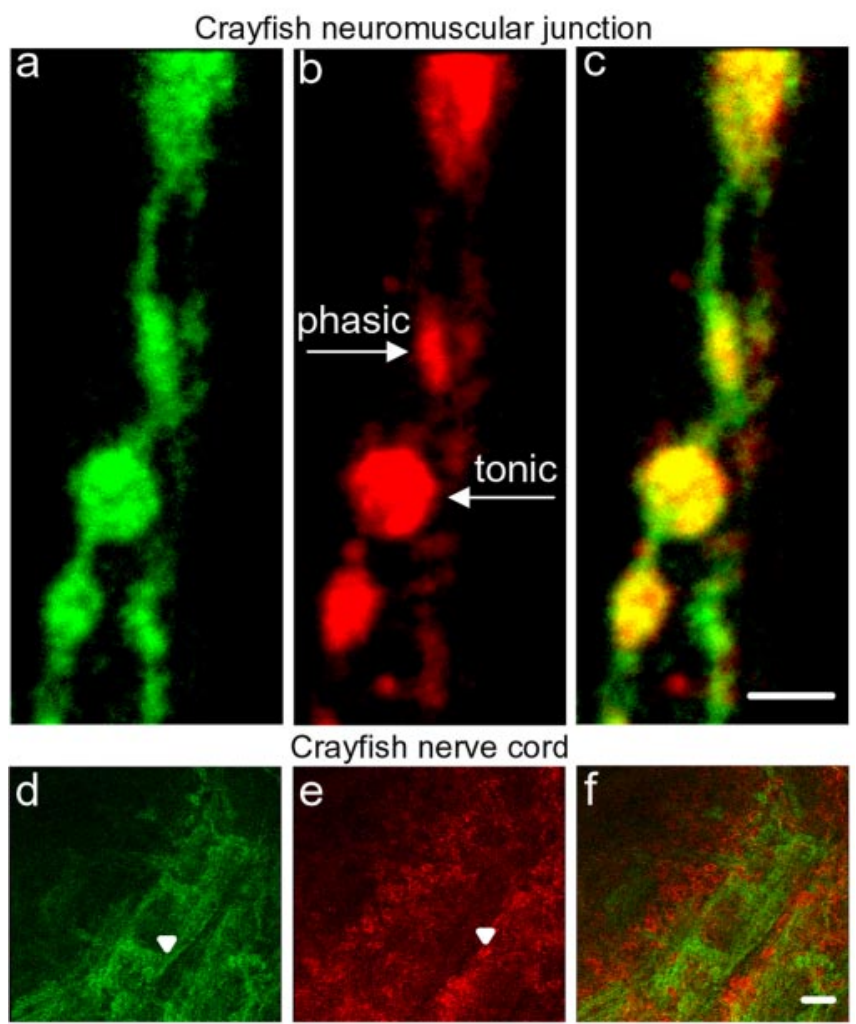

Drosophila ventral ganglion
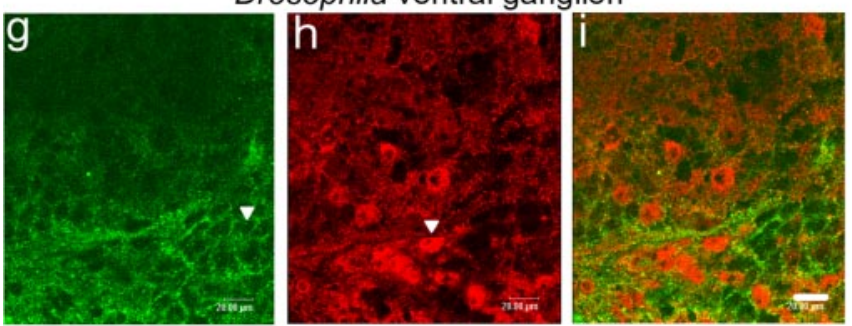

\section{Calcineurin B}
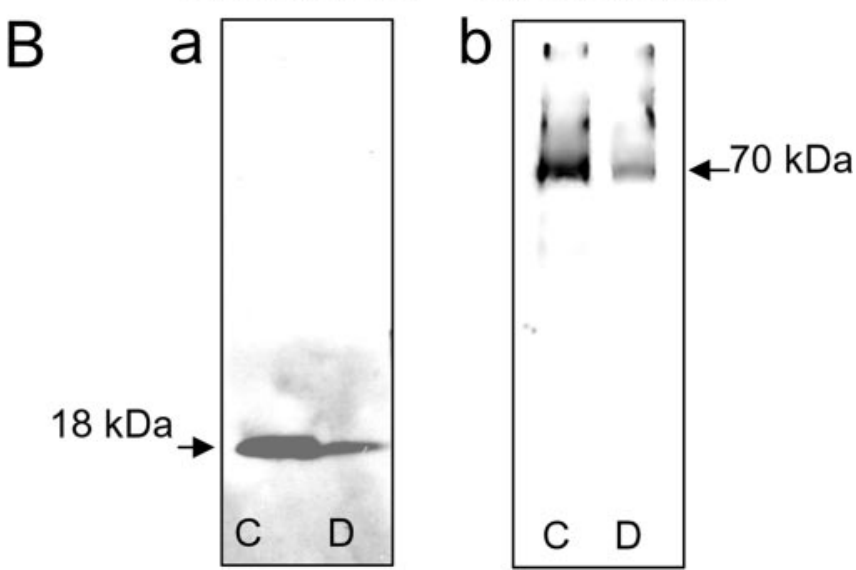

Figure 8. $\quad \boldsymbol{A}$, Example of double immunostaining for calcineurin $\mathrm{B} \alpha(\mathrm{red} ; \boldsymbol{b})$ and syntaxin (green; $\boldsymbol{a}$ ) at motornerveterminals of neuromuscular junction of crayfish extensor muscle showing immunofluorescence in both thin phasic boutons and more varicose endings corresponding to tonic boutons. Ac, Overlay image of $\boldsymbol{a}$ and $\boldsymbol{b}$ in which yellow shows colocalization of antibodies. Calcineurin immunostaining (red) is present in neuronal cell bodies at crayfish nerve cord ( $A \boldsymbol{e}, \boldsymbol{A f}$, arrowhead) and Drosophila ventral ganglion ( $\boldsymbol{A} \boldsymbol{h}, \boldsymbol{A i}$, arrowhead). Scale bar, $4 \mu \mathrm{m}$.
A

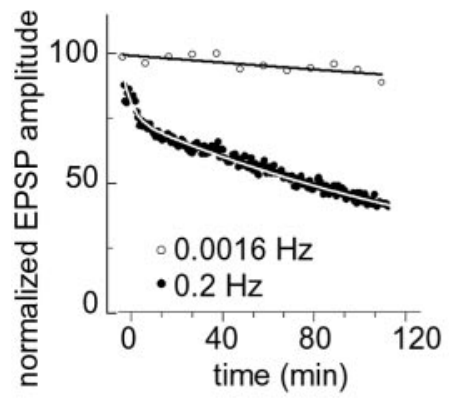

B

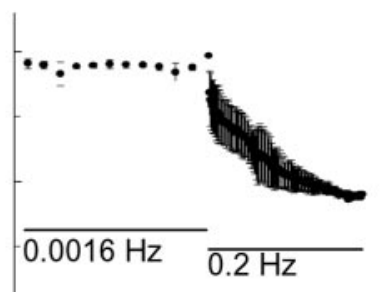

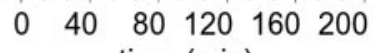

D
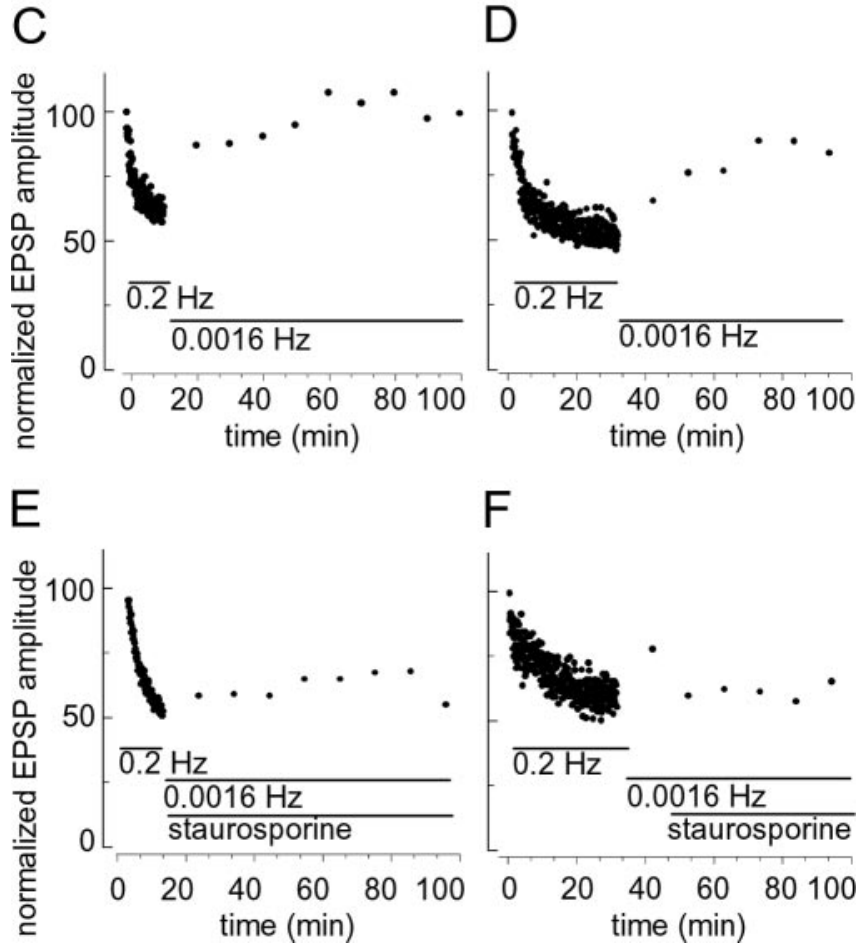

Figure 9. Recovery from LFD requires kinase activity. $A$, Stimulation at $0.0016 \mathrm{~Hz}$ caused minimal depression compared with control stimulation at $0.2 \mathrm{~Hz}(n=3)$. Solid lines represent biexponential best fit through the data. $B, \mathrm{LFD}$ at $0.2 \mathrm{~Hz}$ could occur after 110 min of stimulation at $0.0016 \mathrm{~Hz}$ ( $n=$ 3). C, After 10 min of stimulation at $0.2 \mathrm{~Hz}$, the frequency of stimulation was lowered to $0.0016 \mathrm{~Hz}$, and there was complete recovery from LFD $(n=3)$. $\boldsymbol{D}$, Recovery was almost complete when the stimulation was decreased to $0.0016 \mathrm{~Hz}$ after 30 min of stimulation at $0.2 \mathrm{~Hz}(n=3)$. $\boldsymbol{E}$, Stimulation at 0.0016 $\mathrm{Hz}$ in the presence of staurosporine after $10 \mathrm{~min}$ of stimulation at $0.2 \mathrm{~Hz}$ did not cause recovery from LFD $(n=3)$. $\boldsymbol{F}$, After 30 min of stimulation at $0.2 \mathrm{~Hz}$, recovery was inhibited in the presence of staurosporine $(n=3)$. Staurosporine was added after the firstrecording at $0.0016 \mathrm{~Hz}$ to show that the recovery could occur before staurosporine treatment.

Because phasic axons and terminals have fewer mitochondria than depression-resistant tonic synapses (King et al., 1996; Bradacs et al., 1997; Nguyen et al., 1997), LFD might occur, because there is not enough ATP to maintain transmitter release. How-

$\leftarrow$

Syntaxin immunoreactivity (green) is present atthe crayfish neuropil (Ad,Af, arrowhead) (scale bar, $40 \mu \mathrm{m})$ and within the boundary of neuronal cell bodies at Drosophila ventral ganglia (Ag,Ai, arrowhead) (scale bar, $20 \mu \mathrm{m})$. Ba, Western blot of crayfish and Drosophila regulatory subunit calcineurin $B \alpha$. Crayfish and Drosophila proteins were resolved by electrophoresis, transferred to nitrocellulose, and probed with anticalcineurin B antibody. Proteins were visualized using a goat antibody conjugated to HRP and a chemiluminescence detection system. A single band of $\sim 18 \mathrm{kDa}$ was detected in both crayfish (laneC) and Drosophila (lane D). Bb, Detection of the crayfish and Drosophila catalytic subunit calcineurin A $\alpha$ by Western blot analysis. The antibody recognizes a single protein band of $\sim 70 \mathrm{kDa}$. 
ever, our data indicate that ATP is readily available for phosphorylation of substrates even after pronounced LFD; phosphatase inhibition after $90 \mathrm{~min}$ of LFD enhanced transmitter release (Fig. $5 C)$, and this would have required adequate [ATP] to support phosphorylation by kinases.

\section{Phosphorylation and depression in other systems}

Crayfish LFD shares striking similarities with LFD that occurs at the synapse between neonatal rat spinal $I_{\mathrm{a}}$ afferents and motoneurons in that both are biphasic, dependent on the frequency of stimuli, and likely because of decreases in transmitter release (Lev-Tov and Pinco, 1992). A similar frequency-dependent LFD attributable to a lowered probability of transmitter release is found at the rat visual cortex (Akaneya et al., 2003).

Although most forms of hippocampal LTD are postsynaptic in origin, there are several forms of LTD that result from a decline in transmitter release (Choi and Lovinger, 1997; Margrie et al., 1998; Li et al., 2004).

Phosphorylation-dependent mechanisms of synaptic transmission depression are found at the cerebellum and hippocampus. Inhibition of calcineurin blocks induction of LTD in rat visual cortex (Torii et al., 1995). Phosphatase inhibition enhances LTD in Purkinje cells but has an opposite effect in pyramidal cells, where it blocks LTD (Ajima and Ito, 1995). In the hippocampus, phosphatase inhibitors inhibit LTD induction (Mulkey et al., 1993) in contrast to the finding in the cerebellum.

$\mathrm{Ca}^{2+}$-dependent activation of PP1 or PP2A and calcineurin is required for the maintenance of LTD (Mulkey et al., 1993, 1994). The dephosphorylation and inactivation of inhibitor-1 by calcineurin activates serine/threonine PP1 activity and contributes to the generation of LTD (Mulkey et al., 1994). LTD in adult hippocampus in vivo involves a decrease in PKC activity that is mediated in part by dephosphorylation of catalytic domain of PKC by protein phosphatases activated after LTD-inducing stimulation (Thiels et al., 2000).

\section{Summary}

This study identifies a role for phosphorylation in one form of long-term plasticity, LFD, at a crayfish phasic neuromuscular synapse. The simplicity of this Arthropod preparation with its presynaptic accessibility and fewer genes, proteins, cells, and connections than mammalian brain tissue, may allow additional progress on the mechanism of depression.

\section{References}

Ajima A, Ito M (1995) A unique role of protein phosphatases in cerebellar long-term depression. NeuroReport 6:297-300.

Akaneya Y, Altinbaev RS, Bayazitov IT, Kinoshita S, Voronin LL, Tsumoto T (2003) Low-frequency depression of synaptic responses recorded from rat visual cortex. Neuroscience 117:305-320.

Atwood HL, Karunanithi S (2002) Diversification of synaptic strength: presynaptic elements. Nat Rev Neurosci 3:497-516.

Atwood HL, Parnas H, Parnas I, Wojtowicz JM (1987) Quantal currents evoked by graded intracellular depolarization of crayfish motor axon terminals. J Physiol (Lond) 383:587-599.

Atwood HL, Dixon D, Wojtowicz JM (1989) Rapid introduction of longlasting synaptic changes at crustacean neuromuscular-junction. J Neurobiol 20:373-385.

Beaumont V, Zucker RS (2000) Enhancement of synaptic transmission by cyclic AMP modulation of presynaptic $I_{\mathrm{h}}$ channels. Nat Neurosci 3:133-141.

Beaumont V, Zhong N, Fletcher R, Froemke RC, Zucker RS (2001) Phosphorylation and local presynaptic protein synthesis in calcium- and calcineurin-dependent induction of crayfish long-term facilitation. Neuron 32:489-501.

Betz A, Ashery U, Rickmann M, Augustin I, Neher E, Sudhof TC, Rettig J,
Brose N (1998) Munc13-1 is a presynaptic phorbol ester receptor that enhances neurotransmitter release. Neuron 21:123-136.

Bittner GD, Harrison J (1970) A reconsideration of the Poisson hypothesis for transmitter release at the crayfish neuromuscular junction. J Physiol (Lond) 206:1-23.

Bradacs H, Cooper R, Msghina M, Atwood H (1997) Differential physiology and morphology of phasic and tonic motor axons in a crayfish limb extensor muscle. J Exp Biol 200:677-691.

Bruner J, Kennedy D (1970) Habituation: occurrence at a neuromuscular junction. Science 169:92-94.

Bryan JS, Atwood H (1981) Two types of synaptic depression at synapses of a single crustacean motor axon. Behav Physiol 8:99-121.

Choi S, Lovinger DM (1997) Decreased frequency but not amplitude of quantal synaptic responses associated with expression of corticostriatal long-term depression. J Neurosci 17:8613-8620.

Colbran RJ (2004) Protein phosphatases and calcium/calmodulindependent protein kinase II-dependent synaptic plasticity. J Neurosci 24:8404-8409.

Coussens CM, Teyler TJ (1996) Protein kinase and phosphatase activity regulate the form of synaptic plasticity expressed. Synapse 24:97-103.

Delaney KR, Zucker RS, Tank DW (1989) Calcium in motor nerve terminals associated with posttetanic potentiation. J Neurosci 9:3558-3567.

Delaney K, Tank DW, Zucker RS (1991) Presynaptic calcium and serotonin-mediated enhancement of transmitter release at crayfish neuromuscular junction. J Neurosci 11:2631-2643.

Dixon D, Atwood HL (1989a) Conjoint action of phosphatidylinositol and adenylate cyclase systems in serotonin-induced facilitation at the crayfish neuromuscular junction. J Neurophysiol 62:1251-1259.

Dixon D, Atwood HL (1989b) Adenylate cyclase system is essential for longterm facilitation at the crayfish neuromuscular junction. J Neurosci 9:4246-4252.

Dostmann WRG, Taylor SS, Genieser HG, Jastorff B, Doskeland SO, Ogreid D (1990) Probing the cyclic-nucleotide binding-sites of cAMPdependent protein kinase-I and kinase-II with analogs of adenosine $3^{\prime}, 5^{\prime}$ cyclic phosphorothioates. J Biol Chem 265:10484-10491.

Dubinsky JM, Fischbach GD (1990) A role for cAMP in the development of functional neuromuscular transmission. J Neurobiol 21:414-426.

Friedrich RW, Molnar GF, Schiebe M, Mercier AJ (1998) Protein kinase C is required for long-lasting synaptic enhancement by the neuropeptide DRNFLRF amide in crayfish. J Neurophysiol 79:1127-1131.

Guerini D, Montell C, Klee CB (1992) Molecular cloning and characterization of the genes encoding the 2 subunits of Drosophila melanogaster calcineurin. J Biol Chem 267:22542-22549.

Hansel C, Linden DJ (2000) Long-term depression of the cerebellar climbing fiber-Purkinje neuron synapse. Neuron 26:473-482.

Hilfiker S, Czernik AJ, Greengard P, Augustine GJ (2001) Tonically active protein kinase A regulates neurotransmitter release at the squid giant synapse. J Physiol (Lond) 531:141-146.

Hua SY, Charlton MP (1999) Activity-dependent changes in partial VAMP complexes during neurotransmitter release. Nat Neurosci 2:1078-1083.

Hua SY, Raciborska DA, Trimble WS, Charlton MP (1998) Different VAMP/synaptobrevin complexes for spontaneous and evoked transmitter release at the crayfish neuromuscular junction. J Neurophysiol 80:3233-3246.

Katz B, Miledi R (1967) A study of synaptic transmission in absence of nerve impulses. J Physiol (Lond) 192:407-436.

Kennedy D, Takeda K (1965) Reflex control of abdominal flexor muscles in the crayfish. J Exp Biol 43:211-227.

King MJ, Atwood HL, Govind CK (1996) Structural features of crayfish phasic and tonic neuromuscular terminals. J Comp Neurol 372:618-626.

Kudo N, Yamada T (1985) Development of the monosynaptic stretch reflex in the rat: an in vitro study. J Physiol (Lond) 369:127-144.

Kuromi H, Yoshihara M, Kidokoro Y (1997) An inhibitory role of calcineurin in endocytosis of synaptic vesicles at nerve terminals of Drosophila larvae. Neurosci Res 27:101-113.

Kunz J, Hall MN (1993) Cyclosporine-A, FK506 and rapamycin- more than just immunosuppression. Trends Biochem Sci 18:334-338.

Lev-Tov A, Pinco M (1992) In vitro studies of prolonged synaptic depression in the neonatal rat spinal cord. J Physiol (Lond) 447:149-169.

Li C, Lu J, Wu C, Duan S, Poo M (2004) Bidirectional modification of presynaptic neuronal excitability accompanying spike timing-dependent synaptic plasticity. Neuron 41:257-268. 
Lin JW, Fu Q (2005) Modulation of available vesicles and release kinetics at the inhibitor of the crayfish neuromuscular junction. Neuroscience 130:889-895.

Lnenicka GA (1991) The role of activity in the development of phasic and tonic synaptic terminals. Ann NY Acad Sci 627:197-211.

Margrie TW, Rostas JA, Sah P (1998) Presynaptic long-term depression at a central glutamatergic synapse: a role for CaMKII. Nat Neurosci $1: 378-383$.

Millar AG, Bradacs H, Charlton MP, Atwood HL (2002) Inverse relationship between release probability and readily releasable vesicles in depressing and facilitating synapses. J Neurosci 22:9661-9667.

Msghina M, Millar AG, Charlton MP, Govind CK, Atwood HL (1999) Calcium entry related to active zones and differences in transmitter release at phasic and tonic synapses. J Neurosci 19:8419-8434.

Mulkey RM, Herron CE, Malenka RC (1993) An essential role for protein phosphatases in hippocampal long-term depression. Science 261:1051-1055.

Mulkey RM, Endo S, Shenolikar S, Malenka RC (1994) Involvement of a calcineurin/inhibitor-1 phosphatase cascade in hippocampal long-term depression. Nature 369:486-488.

Nguyen PV, Marin L, Atwood HL (1997) Synaptic physiology and mitochondrial function in crayfish tonic and phasic motor neurons. J Neurophysiol 78:281-294.

Ramakers GM, Heinen K, Gispen WH, de Graan PN (2000) Long term depression in the CA1 field is associated with a transient decrease in preand postsynaptic PKC substrate phosphorylation. J Biol Chem 275:28682-28687.

Stewart BA, Atwood HL, Renger JJ, Wang J, Wu CF (1994) Improved stability of Drosophila larval neuromuscular preparations in hemolimphlike physiological solutions. J Comp Physiol [A] 175:179-191.

Sharma SK, Bagnall MW, Sutton MA, Carew TJ (2003) Inhibition of calcineurin facilitates the induction of memory for sensitization in Aplysia: requirement of mitogen-activated protein kinase. Proc Natl Acad Sci USA 100:4861-4866

Swain JE, Robitaille R, Dass GR, Charlton MP (1991) Phosphatases modulate transmission and serotonin facilitation at synapses: studies with the inhibitor okadaic acid. J Neurobiol 22:855-864.
Terada H, Matsushita M, Lu YF, Shirai T, Li ST, Tomizawa K, Moriwaki A, Nishio S, Date I, Ohmoto T, Matsui H (2003) Inhibition of excitatory neuronal cell death by cell-permeable calcineurin autoinhibitory peptide. J Neurochem 87:1145-1151.

Thiels E, Kanterewicz BI, Knapp LT, Barrionuevo G, Klann E (2000) Protein phosphatase-mediated regulation of protein kinase $\mathrm{C}$ during long-term depression in the adult hippocampus in vivo. J Neurosci 20:7199-7207.

Tokuda M, Hatase O (1998) Regulation of neuronal plasticity in the central nervous system by phosphorylation and dephosphorylation. Mol Neurobiol 17:137-156.

Torii N, Kamishita T, Otsu Y, Tsumoto T (1995) An inhibitor for calcineurin, FK-506, blocks induction of long-term depression in rat visual cortex. Neurosci Lett 185:1-4.

Van Harreveld A (1936) A physiological solution for freshwater crustaceans. Proc Soc Exp Biol 36:428-432.

Wojtowicz JM, Atwood HL (1984) Presynaptic membrane potential and transmitter release at the crayfish neuromuscular junction. J Neurophysiol 52:99-113.

Wojtowicz JM, Atwood HL (1986) Long-term facilitation alters transmitter releasing properties at the crayfish neuromuscular junction. J Neurophysiol 55:484-498.

Yamada A, Yoshio M, Nakamura A, Kohama K, Oiwa K (2004) Protein phosphatase $2 \mathrm{~B}$ dephosphorylates twitchin, initiating the catch state of invertebrate smooth muscle. J Biol Chem 279:40762-40768.

Yasuda H, Higashi H, Kudo Y, Inoue T, Hata Y, Mikoshiba K, Tsumoto T (2003) Imaging of calcineurin activated by long-term depressioninducing synaptic inputs in living neurons of rat visual cortex. Eur J Neurosci 17:287-297.

Yawo H (1999a) Protein kinase C potentiates transmitter release from the chick ciliary presynaptic terminal by increasing the exocytotic fusion probability. J Physiol (Lond) 515:169-180.

Yawo H (1999b) Two components of transmitter release from the chick ciliary presynaptic terminal and their regulation by protein kinase C. J Physiol (Lond) 516:461-470.

Zucker RS, Bruner J (1977) Long-lasting depression and the depletion hypothesis at crayfish neuromuscular junction. J Comp Physiol [A] 121: 223-240. 